Research Paper

\title{
Parthenolide Inhibits Cancer Stem-Like Side Population of Nasopharyngeal Carcinoma Cells via Suppression of the NF-кB/COX-2 Pathway
}

\author{
Kun Liao ${ }^{2 *}$, Bin Xia 2*, Qun-Ying Zhuang 1, Meng-Jun Hou 2, Yu-Jing Zhang 2, Bing Luo 1, Yang Qiu ${ }^{1}$, \\ Yan-Fang Gao 2, Xiao-Jie Li 2, Hui-Feng Chen 2, Wen-Hua Ling 2, Cheng-Yong He 1, Yi-Jun Huang 3 , \\ Yu-Chun Lin ${ }^{1,2}$, Zhong-Ning Lin $1,2 \bowtie$ \\ 1. State Key Laboratory of Molecular Vaccinology and Molecular Diagnostics, School of Public Health, Xiamen University, Xiamen Fujian 361102, \\ PR China. \\ 2. Guangdong Provincial Key Laboratory of Food, Nutrition and Health, School of Public Health, Sun Yat-sen University, Guangzhou 510080, PR \\ China. \\ 3. Zhongshan School of Medicine, Sun Yat-sen University, Guangzhou 510080, PR China.
}

*These authors contributed equally to this work.

$\triangle$ Corresponding author: State Key Laboratory of Molecular Vaccinology and Molecular Diagnostics, School of Public Health, Xiamen University, Xiang'an Nan Road, Xiamen, Fujian 361102, PR China. Tel: +86-592-288 0615; fax: +86-592-218 7358. E-mail: linzhn@xmu.edu.cn (Z.-N. Lin) or linych@xmu.edu.cn (Y.-C. Lin).

(C) Ivyspring International Publisher. This is an open-access article distributed under the terms of the Creative Commons License (http://creativecommons.org/ licenses/by-nc-nd/3.0/). Reproduction is permitted for personal, noncommercial use, provided that the article is in whole, unmodified, and properly cited.

Received: 2013.12.18; Accepted: 2014.11.23; Published: 2015.01.01

\begin{abstract}
Cancer stem cells play a central role in the pathogenesis of nasopharyngeal carcinoma and contribute to both disease initiation and relapse. In this study, cyclooxygenase-2 (COX-2) was found to regulate cancer stem-like side population cells of nasopharyngeal carcinoma cells and enhance cancer stem-like cells' characteristics such as higher colony formation efficiency and overexpression of stemness-associated genes. The regulatory effect of COX-2 on cancer stem-like characteristics may be mediated by ABCG2. COX-2 overexpression by a gain-of-function experiment increased the proportion of side population cells and their cancer stemness properties. The present study also demonstrated that in contrast to the classical chemotherapy drug 5-fluorouracil, which increased the proportion of side population cells and upregulated the expression of COX-2, parthenolide, a naturally occurring small molecule, preferentially targeted the side population cells of nasopharyngeal carcinoma cells and downregulated COX-2. Moreover, we found that the cancer stem-like cells' phenotype was suppressed by using COX-2 inhibitors NS-398 and CAY 10404 or knocking down COX-2 with siRNA and shRNA. These findings suggest that COX-2 inhibition is the mechanism by which parthenolide induces cell death in the cancer stem-like cells of nasopharyngeal carcinoma. In addition, parthenolide exhibited an inhibitory effect on nuclear factor-kappa B (NF-kB) nucler translocation by suppressing both the phosphorylation of $I \kappa B$ kinase complex and $I \kappa B \alpha$ degradation. Taken together, these results suggest that parthenolide may exert its cancer stem cell-targeted chemotherapy through the NF-KB/COX-2 pathway.
\end{abstract}

Key words: parthenolide, nasopharyngeal carcinoma, cyclooxygenase-2, nuclear factor-kappa B, side population cells.

\section{Introduction}

Nasopharyngeal carcinoma (NPC) has a high incidence in southern China, especially in the Can- tonese region around Guangzhou, where the incidence is approximately $30-80 / 100,000$ population per 
year $[1,2]$. The overall five-year survival for all NPC stages ranges from $50 \%$ to $70 \%$ [3]. Although advances in radiation and chemotherapy have improved the prognosis of individuals with NPC, many patients still succumb to the disease due to therapeutic resistance and metastasis $[1,3]$. These treatment failures probably result from residual tumor cells remaining after standard therapies. A better understanding of the biology of NPC and developing novel theranostic strategies to eliminate therapy-resistant tumor cells are important $[2,4]$.

Recent studies have suggested that cancer stem cells (CSCs), a small subset of cells in tumors which possess stem cell properties, may be responsible for tumorigenesis and may contribute to resistance of NPC to traditional chemotherapy [5-8]. Specifically, CSCs with high levels of drug transporters such as ATP-binding cassette $(\mathrm{ABC})$ transporters, including their sub-family $\mathrm{G}$ member 2 (ABCG2), are resistant to xenobiotics due to their ability to actively extrude drugs out of cells $[6,9]$.

Side population (SP) cells have been identified from various cancer cell lines and primary tumor tissues, including NPC and hepatocellular, lung, and gastric cancers, and have been shown to express high levels of stem cell-associated genes and possess multi-potent capabilities such as differentiation, proliferation, and self-renewal potential, suggesting that these cells exhibit stem cell properties [10-12]. Recently, a technique has been developed to isolate SP cells using flow cytometry. SP cells have been sorted from five NPC cell lines, including C-666-1, CNE1, HONE-1, CNE2 and SUNE-1, and their presence ranged from $0.1 \%$ to $6.8 \%$ of the total cell population [10]. An in vivo experiment showed that the injection of SP cells sorted from CNE2 cells into nonobese diabetic/severe combined immunodeficient (NOD/SCID) mice led to tumor formation. The tumor forming ability of SP cells was about 20 times higher than non-side population (NSP) cells [10]. Therefore, SP cells can be considered a type of stem-like cancer cell in the NPC cell population.

To date, the mainstream treatment for NPC has been radiotherapy or combined chemo-radiotherapy; however, application of chemotherapy has become popular recently and a classical anticancer drug, 5 -fluorouracil (5-FU), is one of the commonly used drugs [4]. Some malignant stem cells in NPC are refractory to these chemotherapeutical drugs [5-8], so it is important to identify novel therapies, such as chemopreventative agents that specifically target the CSC population of NPC.

Parthenolide, a naturally occurring small molecule, is a major sesquiterpene lactone responsible for the bioactivity of feverfew (Tanacetum parthenium Sch.
Bip.), which is a traditional herbal plant that has been used for the treatment of fever, migraine, and arthritis [13]. In our previous study, parthenolide inhibited proliferation and induced apoptosis sensitivity of NPC cells [14]. Studies have reported that parthenolide killed melanoma cells without affecting normal melanocytes [15], selectively eliminated osteosarcoma cells but not non-malignant osteoblasts [16], and preferential targeted CSCs for apoptosis while sparing normal stem cells in leukemia and solid tumors [17-20]. Conventional chemotherapeutic drugs often act primarily on replicating bulk tumor cells while sparing CSCs [21]. For example, parthenolide completely abolished melanospheres even a dose of 5 $\mu \mathrm{M}$ whereas dacarbazine (the first-line anti-melanoma drug) only kills up to $70 \%$ of melanoma CSCs at $2 \mathrm{mM}$ [22]. Recent studies have shown that parthenolide can reduce the viability of CSCs in various cancers, including leukemia, breast cancer, osteosarcoma, melanoma, mesenchymal tumors, and prostatic carcinoma [20]. Importantly, an adequate safety profile for parthenolide has been shown in Phase I/II clinical trials $[23,24]$. Whether parthenolide can target CSCs of NPC has not been explored. The current study was designed to investigate the effect of parthenolide on NPC stem-like cells.

The transcription factor nuclear factor-kappa B $(\mathrm{NF}-\kappa \mathrm{B})$ is one of the key regulators involved in immune and inflammatory responses [25]. Growing evidence has indicated that the NF- $\kappa \mathrm{B}$ signaling pathway is a central coordinator for carcinogenesis [26]. $\mathrm{NF}-\kappa \mathrm{B}$ has been detected in many malignant tumors and also in NPC tissues [27]. In addition, studies have shown that NF-kB is activated in leukemia and breast cancer stem cells $[28,29]$, and the NF- $\kappa B$ pathway can be selectively targeted to preferentially inhibit stem-like cells in breast cancer [21] and leukemia [17, 30].

Cyclooxygenase-2 (COX-2), also called prostaglandin-endoperoxide synthase 2 (PTGS2), a downstream molecule of the NF- $\mathrm{BB}$ pathway [31], is commonly upregulated in various human cancers [32]. COX-2 produces prostaglandin E2 (PGE2) in cancer cells [31], while PGE2 favors carcinogenesis by enhancing cellular resistance to apoptosis and the potential for invasiveness, angiogenesis, proliferation, and metastasis [33]. Recent studies have shown that stem-like $\mathrm{CD}_{133^{+}}$glioblastoma cells have higher COX-2 expression than CD133- cells [34]. In addition, COX-2 inhibitors enhance the therapeutic effects of radiation on CSCs in a variety of tumors, including glioblastoma [34], melanoma, and oral carcinoma [35]. Most recently, global gene expression analysis of osteosarcoma stem cells has revealed a potentially significant role for COX-2 in tumor initiation [36]. These 
data suggest that COX-2 may be a meaningful target for specific killing of CSCs in chemotherapy strategies.

In this study, we investigated the role of COX-2 in regulating the cancer stem-like side population of nasopharyngeal carcinoma cells. We also studied the inhibiting effect of parthenolide on NPC SP cells and the underlying mechanisms. Our data suggest that suppression of cancer stem-like cells by parthenolide may be via the NF-kB/COX-2 signaling pathway, and COX-2 is a potential theranostic target for parthenolide's killing of NPC cancer stem-like cells.

\section{Methods}

\section{Cell culture and reagents}

It has been reported that cancer stem-like SP cells were isolated from CNE1 and CNE2 [10], so CNE1 and CNE2 cells were used in the present study. (Of human NPC cell lines, CNE1 is well-differentiated, and CNE2 is poorly-differentiated). CNE1, CNE2, and 293T cells were obtained from the Cancer Center of Sun Yat-sen University (Guangzhou, China). The cells were maintained in RPMI 1640 medium supplemented with 10\% fetal bovine serum (FBS) (Hyclone, UT, USA), $100 \mathrm{U} / \mathrm{mL}$ penicillin $\mathrm{G}$, and $100 \mu \mathrm{g} / \mathrm{mL}$ streptomycin in a humidified incubator at $37^{\circ} \mathrm{C}$ with $5 \% \mathrm{CO}_{2}$. 3-(4,5-dimethylthiazol-2-yl)-2,5-diphenyltetrazoliumbromide (MTT), Hoechst 33342, verapamil, dimethyl sulfoxide (DMSO), parthenolide (PN), pyrrolidine dithiocarbamate (PDTC), tumor necrosis factor- $\alpha$ (TNF- $\alpha$ ), and 5-fluorouracil (5-FU) were from Sigma-Aldrich (MI, USA). The COX-2 inhibitors NS-398 and CAY10404 were purchased from Cayman Chemical (MI, USA). TRIzol was purchased from Invitrogen (CA, USA).

\section{Vector construction and establishment of COX-2 overexpressing stable cell lines}

In order to establish stable cell lines overexpressing COX-2, PTGS2 mRNA was incorporated into a pBabe-puro retroviral vector (a kind gift from Dr. Wen Chen, Sun Yat-sen University, China) for introduction into CNE1 and CNE2 cells. To construct the pBabe-PTGS2-FLAG recombinant plasmid, a Flag-tagged PTGS2 fragment was first isolated from a plasmid cDNA library (a kind gift from Dr. Jiahuai Han, Xiamen University, China) by RT-PCR with specific primers for PTGS2 (forward 5'-ATT AGG ATC CAT GCT CGC CCG CGC CCT-3' and reverse 5'-GAG TCG ACT TAC TTA TCG TCG TCA TCC TTG TAA TCC AGT TCA GTC GAA CGT TCT TT-3'). The isolated DNA fragment was then inserted into the pBabe-puro vector. The viruses were packaged in 293T cells according to the standard protocol. Briefly, amphotropic retroviruses were produced by transfection of the $293 \mathrm{~T}$ producer cell with a ratio of 1:1 retroviral vector to a vector encoding a replication-defective helper virus, pCL-Ampho (a kind gift from Dr. Wen Chen, Sun Yat-sen University, China), using the X-tremeGENE HP DNA Transfection Reagent (Roche Molecular Biochemicals, IN, USA). pBabe-PTGS2-FLAG and pBabe empty vector were introduced separately into CNE1 and CNE2 cells by retroviral infection; CNE1 and CNE2 cells were screened for transformation with $0.7 \mu \mathrm{g} / \mathrm{mL}$ and 1 $\mu \mathrm{g} / \mathrm{mL}$ puromycin, respectively. The COX-2overexpressing cell lines, named CNE1-PTGS2 and CNE2-PTGS2 cells, were identified by the measurement of PTGS2 mRNA and COX-2 protein levels. The corresponding control cells were called CNE1-pB and CNE2-pB cells.

\section{Vector construction and establishment of stable COX-2 knockdown cell lines}

Both pLKO.1 lentiviral short hairpin RNA (shRNA) vector and control shRNA targeting green fluorescent protein were gifts from Dr. Wen Chen. The PTGS2-shRNA targeting sequence (5'-CCA GGG CTC AAA CAT GAT GTT-3'), corresponding to positions 665-685 of human PTGS2 mRNA (Gene Bank Accession: NM000963.1), was designed using the RNAi Consortium website [37]. The sense and antisense oligonucleotides were annealed and ligated into the $\mathrm{pLKO} .1$ vector. The viruses were then packaged in 293T cells according to the standard protocol. Briefly, amphotropic lentiviruses were produced by transfection of the 293T producer cell with a mixture of a lentiviral vector, a packaging plasmid (pCMV-delta 8.9), and envelope plasmid (VSVG) in the ratio of 8:8:1, using the X-tremeGENE HP DNA Transfection Reagent. To generate stable PTGS2 knockdown cells, pLKO-PTGS2-shRNA recombinant plasmid was introduced into CNE1 or CNE2 cells by lentiviral infection and screened with $0.7 \mu \mathrm{g} / \mathrm{mL}$ and $1 \mu \mathrm{g} / \mathrm{mL}$ puromycin, respectively. The established COX-2 knockdown NPC cell lines were identified and named CNE1-shPTGS2 and CNE2-shPTGS2 cells. The corresponding control cells were CNE1-shCtrl and CNE2-shCtrl cells.

\section{Small interfering RNA (siRNA) transfection for partial PTGS2 knockdown}

PTGS2 siRNA and a negative control oligonucleotide duplex, for use as a control, were designed and synthesized by Ribobio Company (Guangzhou, China). The specific PTGS2 siRNA sequence was: 5'-GCA GCT TCC TGA TTC AAA T-3'. CNE1 and CNE2 cells were plated at $50 \%$ confluence in a six-well plate in RPMI 1640 without antibiotics. After $24 \mathrm{~h}$, the 
PTGS2 siRNA or negative control (50 nM) was transfected into cells with Lipofectamine 2000 (Invitrogen, Carlsbad, CA, USA) according to the manufacturer's instructions.

\section{Hoechst 33342 staining and SP cell sorting using flow cytometry analysis}

Following Wang et al.'s method [10], cells were digested with $0.25 \%$ trypsin-EDTA (Life Technologies, CA, USA), washed with calcium/magnesium-free PBS, and resuspended in RPMI 1640 supplemented with $2 \%$ FBS at a density of $1 \times 10^{6}$ cells/mL. Hoechst $33342(5 \mu \mathrm{g} / \mathrm{mL})$, a DNA binding dye, was then added, and the cells were incubated for $90 \mathrm{~min}$ in the dark at $37^{\circ} \mathrm{C}$ with interval mixing. Simultaneously, for a control as explained below, a subset of cells was incubated with $100 \mu \mathrm{M}$ verapamil, a calcium ion tunnel antagonist-sensitive $\mathrm{ABC}$ transporter, for $30 \mathrm{~min}$ at $37^{\circ} \mathrm{C}$ before the addition of Hoechst 33342. The cells were washed twice with ice-cold PBS (supplemented with $2 \%$ FBS), and then analyzed and sorted using BD Influx ${ }^{\mathrm{TM}}$ flow cytometry (Becton Dickinson, CA, USA). The Hoechst dye was excited with the UV laser at $350 \mathrm{~nm}$ and its fluorescence was measured with a 450/20 BP filter (Hoechst Blue) and a 675 EFLP optical filter (Hoechst Red). The SP phenotype was characterized by low blue and red fluorescence intensity on a dot-plot displaying dual-wavelength fluorescence of blue versus red detected at 450 and $675 \mathrm{~nm}$, respectively. As a control, verapamil was added to block the activity of Hoechst 33342 transporter [9], and the SP gate, indicated by the blue polygon near the origin of each cell sorting plot, was defined as the diminished region in the presence of verapamil. The ratio of SP to NSP cells was calculated. Both SP and NSP cells were collected for further experiments.

\section{Cell colony formation assay}

To assess the cells' self-renewal ability, a total of 300 cells/well (low-density inoculation) was seeded into each well of a six-well plate in the colony formation assay. The cells, including total NPC cells and freshly sorted SP and NSP cells, were treated with parthenolide $(1$ or $5 \mu \mathrm{M})$ or one of the selective COX-2 inhibitors NS-398 $(20 \mu \mathrm{M})$ or CAY10404 $(20 \mu \mathrm{M})$, for three days. Then the cells were incubated with fresh RPMI 1640 complete medium for another four days. Control cells were incubated with complete culture medium without treatment for seven days. After most of the cells had formed colonies of $>50$ cells, the cells were washed twice with ice-cold PBS, fixed in methanol for $15 \mathrm{~min}$, and dyed with crystal violet for 15 min at room temperature. After the dye was washed out, the cell colonies that contained $>50$ cells had their areas measured and the colonies were counted using a phase-contrast microscope (Carl Zeiss AG, Oberkochen, Germany), as previously reported [10]. This assay was repeated at least three times. The colony formation efficiency (CFE) was the ratio (\%) of the colony number to the plated cell number.

\section{Quantitative real-time polymerase chain reaction (qRT-PCR)}

Total RNA was extracted from the cells using TRIzol reagent (Invitrogen Corp, NY, USA). cDNA was synthesized from $1 \mu \mathrm{g}$ of total RNA as the template in a reaction volume of $20 \mu \mathrm{L}$ using TaKaRa reverse transcription reagents (TaKaRa, Otsu, Japan). The mRNA level of genes was detected with SYBR Green I kit (TaKaRa, Otsu, Japan). The relative quantification for the mRNA level of the genes was performed by qRT-PCR using a ViiA ${ }^{\mathrm{TM}} 7$ Real-Time PCR System (Life Technologies, CA, USA). The target gene expression was normalized to the expression of beta actin $(A C T B)$ and analyzed using the $2^{-\Delta \Delta C t}$ relative quantification method [38]. The ratio of the target gene to $A C T B$ was calculated from similar assays performed in triplicate. And three independent experiments were conducted. The qRT-PCR program conditions were: initial denaturation at $95^{\circ} \mathrm{C}$ for $30 \mathrm{~s}$; 40 cycles of $95^{\circ} \mathrm{C}$ for $5 \mathrm{~s}$ and $60^{\circ} \mathrm{C}$ for $30 \mathrm{~s}$. The primer sequences used were: PTGS2 (forward 5'-CAG CCA TAC AGC AAA TCC TTG-3' and reverse 5'-CAA ATG TGA TCT GGA TGT CAA C-3'), ABCG2 (forward 5'-ATA TTA TCG AAT ATC AAT GGG ATC A-3' and reverse 5'-CCA TCA CAA CAT CAT CTT GTA C-3'), OCT4 (also known as POU5F1) (forward 5'-CAA TGA AAA TCT TCA GGA GAT A-3' and reverse 5'-ACC ACA CTC GGA CCA CAT C-3'), KLF4 (forward 5'-CTC CAT TAC CAA GAG CTC AT-3' and reverse 5'-GGT AAG GTT TCT CAC CTG T-3'), NANOG (forward 5'-AAC CTC AGC TAC AAA CAG GT-3' and reverse 5'-AGG TCT GGT TGC TCC ACA T-3'), BMI1 (forward 5'-ACA TTC CTT CTG TAA AAC GTG-3', and reverse 5'-CAT TGG CAG CAT CAG CAG-3'), and ACTB (forward 5'-CAC CAG GGC GTG ATG GT-3' and reverse 5'-CTC AAA CAT GAT CTG GGT CAT-3').

\section{Western blotting analysis}

The cells were lysed in whole-cell lysate buffer containing 1\% NP-40, $5 \mathrm{mM}$ ethylenediaminetetraacetic acid (EDTA), $150 \mathrm{mM} \mathrm{NaCl}, 50 \mathrm{mM}$ Tris- $\mathrm{HCl}$, pH 8.0, 1\% Triton X-100, 1\% PMSF, and 1\% protease inhibitor cocktail. For the analysis of phosphorylated protein, an additional 1\% phosphatase inhibitor cocktail was added to the whole-cell lysate buffer before use. The protein concentrations were measured using the bicinchoninic acid (BCA) protein assay 
(Beyotime, Shanghai, China). Equivalent amounts of protein $(30-70 \mu \mathrm{g})$ from each cell group were resolved by $12 \%$ sodium dodecyl sulfate-polyacrylamide gel electrophoresis (SDS-PAGE) and transferred to PVDF membranes (Millipore, MA, USA). The membranes were blocked with $5 \%$ non-fat dry-milk for $1 \mathrm{~h}$ and then incubated overnight at $4^{\circ} \mathrm{C}$ with antibodies specific to COX-2 (BD BioSciences, CA, USA; dilution 1:250), NF-кB p65 (Santa Cruz, CA, USA; dilution $1: 5,000)$, IKK $\alpha$, IKK $\beta$, IкB $\alpha$, phospho-NF- $\mathrm{B}$ p65, phospho-IKK $\alpha / \beta$, phospho I $\mathrm{B} \alpha$ (Cell Signaling Technology, BSN, USA; dilution 1:1,000), GAPDH (Kangchen, Shanghai, China; dilution 1:2,000), histone H3 (Beyotime, Shanghai, China; dilution 1:1,000), and $\beta$-actin (ProteinTech Group, IL, USA; dilution 1:3,000). The membrane was washed with TBST buffer three times and incubated with the secondary antibodies anti-rabbit IgG or anti-mouse IgG (Santa Cruz, CA, USA) for $1 \mathrm{~h}$ at room temperature. Photographs were taken and the relative blot densities were quantified by scanning the photographic negatives with a gel documentation and analysis system (Thermo Scientific, NC, USA). The blots were stripped and reprobed with $\beta$-actin primary antibody to ensure equivalent loading.

\section{Immunofluorescence assay}

Freshly sorted NSP and SP cells were grown in $35 \mathrm{~mm}$ glass-bottomed dishes (MatTek Corporation, MA, USA) for $48 \mathrm{~h}$ at $37^{\circ} \mathrm{C}$, washed twice with PBS, and fixed in $4 \%$ paraformaldehyde (pH 7.4) for $15 \mathrm{~min}$ at room temperature. The cells were washed twice with PBS and incubated in PBS plus $0.3 \%$ Triton X-100 for $10 \mathrm{~min}$ at room temperature. The cells were washed with PBS, incubated with 3\% FBS for $30 \mathrm{~min}$ at room temperature, and incubated overnight at $4^{\circ} \mathrm{C}$ with COX-2 antibody (dilution 1:30). After washing three times with ice-cold PBS, the cells were incubated with Alexa Fluor ${ }^{\circledR} 594$ goat anti-mouse IgG (Life Technologies Corporation, NY, USA) in the dark for 1 $\mathrm{h}$ at room temperature. After extensive washing with ice-cold PBS, the cell nuclei were counterstained with DAPI (Beyotime, Shanghai, China). The cells were photographed using a confocal microscope (Leica, Germany).

\section{MTT assay of cell proliferation}

The inhibitory effect of parthenolide or 5-FU on the viability of CNE1 and CNE2 cells was determined using the MTT assay [14]. The cells were plated in 96-well plates at a density of $8 \times 10^{3}$ cells/well in triplicate and cultured in medium with or without various concentrations of parthenolide $(1-100 \mu \mathrm{M})$ or 5 -FU $(0.625-80 \mu \mathrm{g} / \mathrm{mL})$. The cells were then grown for an additional $24 \mathrm{~h}$ or $48 \mathrm{~h}$. Then, $20 \mu \mathrm{L}$ of MTT $(5$ $\mathrm{mg} / \mathrm{mL}$ ) was added to each well for $4 \mathrm{~h}$, and the resulting crystals were dissolved in DMSO. The optical density (OD) of each well was measured using the ELx-800 instrument (BioTek, VT, USA) at $570 \mathrm{~nm}$. Wells treated only with DMSO were used as controls and represented $100 \%$ cell survival, and wells without cells were used for blanking the spectrophotometer. The inhibition of the proliferation rate of cells was calculated as follow: $\%=100 \%-\left(\mathrm{OD}_{570}\right.$ sample $-\mathrm{OD}_{570}$ blank $) /\left(\mathrm{OD}_{570}\right.$ control $-\mathrm{OD}_{570}$ blank $) \times 100 \%$. The half-inhibition concentrations $\left(\mathrm{IC}_{50}\right)$ were calculated by the Bliss method to evaluate the inhibitory effect of the treatment. Each assay was repeated at least three times.

\section{Subcellular fractionation}

Cytoplasmic and nuclear extracts were prepared using the method described by Zhang et al with minor modifications [14]. Briefly, the cells were washed with ice-cold PBS and transferred to centrifuge tubes. The cells were then centrifuged at $300 \times \mathrm{g}$ and $4^{\circ} \mathrm{C}$ for 4 min. After centrifugation, the pellets were resuspended in $200 \mu \mathrm{L}$ of fresh ice-cold buffer A [10 mM HEPES (pH 7.9), $10 \mathrm{mM} \mathrm{KCl}, 1 \mathrm{mM}$ DTT, 1\% PMSF, and $1 \%$ protease inhibitor cocktail]. After $15 \mathrm{~min}$, the cells were lysed with NP-40 (at a final concentration of $0.3 \%$ ), and the mixture was vortexed for $10 \mathrm{~s}$ and incubated on ice for $10 \mathrm{~min}$. The nuclei were pelleted by centrifugation at $1,500 \times \mathrm{g}$ and $4^{\circ} \mathrm{C}$ for $5 \mathrm{~min}$, and the supernatant (cytoplasmic extracts) was recovered by centrifugation at $13,000 \times \mathrm{g}$ and $4^{\circ} \mathrm{C}$ for $15 \mathrm{~min}$. The nuclei were washed twice with $400 \mu \mathrm{L}$ of ice-cold buffer $\mathrm{A}$, resuspended in $50 \mu \mathrm{L}$ of fresh ice-cold buffer B [20 mM HEPES (pH 7.9), 400 mM NaCl, 1 mM DTT, $1 \%$ PMSF, $1 \%$ protease inhibitor cocktail], and then incubated on ice for $30 \mathrm{~min}$ at $4^{\circ} \mathrm{C}$. The mixture was then centrifuged at $18,000 \times \mathrm{g}$ and $4^{\circ} \mathrm{C}$ for $30 \mathrm{~min}$, and the supernatant was collected as the nuclear extract. The fraction purity was assessed by electrophoresis followed by blotting and protein detection with histone H3 (nucleus) and GAPDH (cytoplasm) antibodies.

\section{Statistical analysis}

The analysis results were expressed as the means \pm standard deviation (SD). Unless otherwise noted, the statistical significance was determined using two-tailed unpaired Student's $t$ test ( $t$-test) for the comparison of two groups. For the comparison of multiple groups, the statistical significance was determined using one-way analysis of variance (ANOVA) followed by Dunnett's $t$-test (SPSS version 17.0; SPSS, IL, USA). The difference was considered statistically significant when $P<0.05$. 


\section{Results}

Higher SP ratio and expression of COX-2 and stemness-associated genes in CNE2 cells compared to CNEl cells

Using flow cytometry, as shown in Fig. 1A, the SP cells of CNE1 and CNE2 cells were counted using the gates indicated by the polygonal box. The SP cells accounted for $1.52 \%$ and $3.55 \%$ of the total CNE1 and CNE2 cells, respectively. Verapamil, an inhibitor of $\mathrm{ABC}$ transporters, was used as a control to ensure the capture of SP cells by being used to set the gate in cell

A
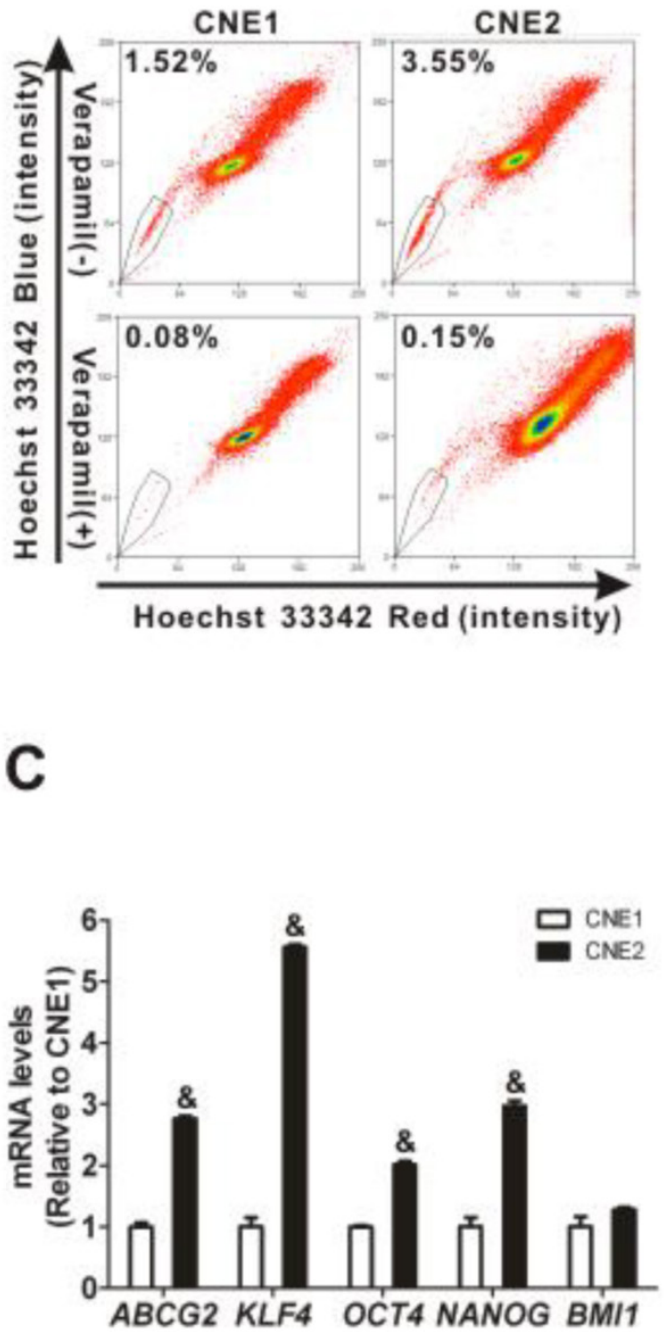

sorting experiments [11]. The percentage of SP cells decreased to $0.08 \%$ and $0.15 \%$ of the total CNE1 and CNE2 cells after preincubating with verapamil for 30 min. Therefore, the experimental condition for the placement of SP gate in the present study was reasonable. Moreover, the quantitative CFEs of CNE1 and CNE2 cells were $20.89 \pm 3.89 \%$ and $47.56 \pm 5.67 \%$, respectively. Significant differences in the relative CFEs were observed between these two cell types, with CNE2 cells $(2.28 \pm 0.27)$ higher than CNE1 cells $(1.00 \pm 0.19)(P<0.01$; Fig. 1B).

B

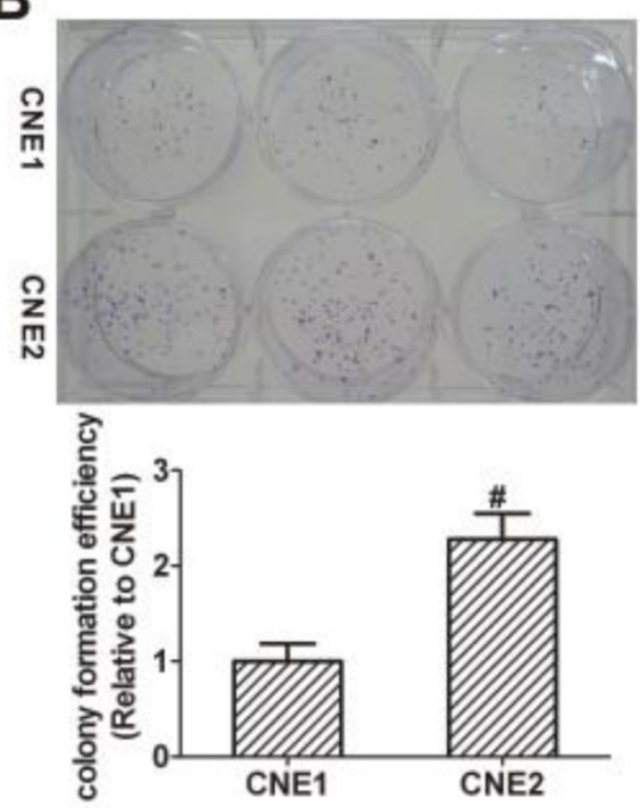

D

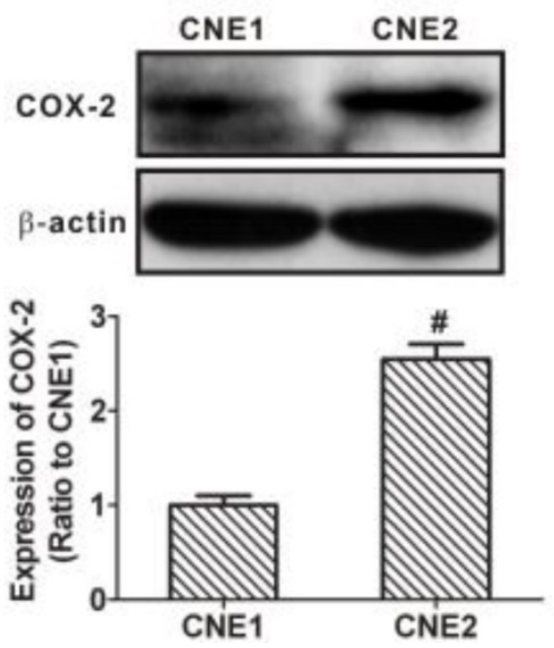

Figure 1. Side population (SP) cell fraction, cell stemness characteristics, and cyclooxygenase-2 (COX-2) expression in CNE1 and CNE2 cells. (A) SP cell identification by flow cytometry (upper row) and control of the SP phenotype with verapamil (lower row). The SP was gated and shown as a percentage of the total cell population. A representative example of the SP proportion is displayed. The percentages of SP cells are indicated in the upper left-hand corners of the panels. The SP assay showed that the proportion of SP cells in CNE2 cells (right) was higher than in CNE1 cells (left). (B) The colony formation assay showed more colonies in the CNE2 cells than in the CNE1 cells (photographs). And the relative colony formation efficiency (CFE) of CNE2 cells was significantly higher than of CNE1 cells (bar graph, \# $P<0.01$ ). The data shown are the means \pm SD of three parallel samples. (C) Quantitative real-time polymerase chain reaction (qRT-PCR) assays showed that the mRNA levels of ABCG2 and stemness-associated genes KLF4, OCT4, and NANOG in CNE2 cells were significantly higher than those in CNE1 cells $(\& P<0.001)$. The target gene expression was normalized to that of beta actin (ACTB). The data shown are the means \pm SD of three experiments for each group. (D) Western blots showed that the expression of COX-2 in CNE2 cells was higher than that in CNE1 cells (\# $P<0.01$ ). $\beta$-Actin is shown as a loading control. The data shown are the means \pm SD of two independent assays. \# $P<0.01$ and \& $P<0.001$ compared with $C N E 1$ cells; the data were analyzed by the $t$-test. 
In addition, when the mRNA level of $A B C G 2$, an important gene that determines the SP phenotype [9], was analyzed, it was significantly higher $(2.76 \pm 0.04)$ in CNE2 cells than that in CNE1 cells $(1.00 \pm 0.06$; $P<$ 0.001 ; Fig. 1C). We also found that the mRNA levels of stemness-associated genes, including KLF4, OCT4, and NANOG, in CNE2 cells were significantly higher than those in CNE1 cells $(P<0.001)$. To assess the relation with stemness, the constitutive protein levels of COX-2 in CNE1 and CNE2 cells were analyzed. The expression level of COX-2 protein in CNE2 cells was higher $(2.55 \pm 0.16$-fold) than in CNE1 cells (1.00 \pm 0.10 -fold; $P<0.01$, Fig. 1D), in agreement with the differences in the SP phenotype. These data showed a higher proportion of SP cells and a higher expression of COX-2 in CNE2 cells than in CNE1 cells.

\section{CSC characteristics and upregulated COX-2 expression in the SP cell fraction of CNE2 cells}

Because CNE2 cells had more SP cells than CNE1 cells (Fig. 1A), SP cells (the R3 gate) and NSP cells (the R4 gate) were sorted from CNE2 cells (Fig. 2A, panel a) for further characterization. The purities of the sorted SP was $96.96 \%$ (Fig. 2A, panel c) and the sorted NSP cells was $99.77 \%$ (Fig. 2A, panel b), respectively. The quantitative CFEs were evaluated for both SP (59.67 \pm $2.85 \%)$ and NSP cells $(28.11 \pm 1.35 \% ; P<0.001)$. As shown in Fig. 2B, SP cells have a higher relative CFE $(2.12 \pm 0.10$-fold) compared to NSP cells (1.00 \pm 0.05-fold). 5-FU was used to test whether or not SP cells possess CSCs' drug resistance. As shown in Fig. $2 \mathrm{C}$, the SP cells increased markedly, from $4.66 \%$ in controls, to $18.92 \%$ and $16.69 \%$ after treatment with 25 and $50 \mu \mathrm{g} / \mathrm{mL} 5-\mathrm{FU}$, respectively. After treatment with 5-FU, gene expression levels in these sorted cells were determined using qRT-PCR and the results showed that both $A B C G 2$ and NANOG were increased in SP cells compared to levels in NSP cells $(P<0.05$, Fig. 2D). Taken together, these characteristics of SP cells, including higher colony forming ability, resistance to the chemotherapeutic agent 5-FU, and increased expression of stem cell-associated genes, suggest that the SP fraction of CNE2 cells displays typical CSC properties.

As shown in Fig. 3A, the level of PTGS2 mRNA in SP cells was 3.37-fold higher than that in NSP cells. Similarly, immunofluorescence analysis revealed that COX-2 protein was more strongly expressed in SP cells than in NSP cells (Fig. 3B). These data demonstrated that there is an increased expression of COX-2 in the cancer stem-like cells of NPC.

\section{Effects of overexpression of COX-2 on the SP phenotype}

To assess the functional relationship between the COX-2 expression and the cancer stemness in NPC cells, we established stable cell lines of CNE1 and CNE2 overexpressing COX-2. The establishment of the two stable cell lines was confirmed at both the transcription and the translation levels. The PTGS2 mRNA levels in COX-2-overexpressing CNE1-PTGS2 cell (2.78 \pm 0.21 -fold) and CNE2-PTGS2 cell (3.72 \pm 0.15 -fold) was significantly increased (both $P<0.01$ ) compared with their counterparts, $\mathrm{pBabe}$ control cells (CNE1-pB and CNE2-pB). As shown in Fig. 4A, higher COX-2 and flag-tagged COX-2 protein levels were also detected in -PTGS2 cells. Both CNE1-PTGS2 and CNE2-PTGS2 cells exhibited increased percentages of SP cells (Fig. 4B). Overexpression of COX-2 markedly enhanced the colony forming ability of CNE1-PTGS2 cells compared with control (-pB) cells (Fig. 4C), and the area of CNE2-PTGS2 cell colonies was larger than that of CNE2-pB cells. In addition, the mRNA levels of ABCG2 and stemness-associated genes OCT4, NANOG and BMI1 were significantly increased in CNE1-PTGS2 and CNE2-PTGS2 cells (Fig. 4D). These results demonstrated that the overexpression of COX-2 increased the cancer stem-like cells phenotype in NPC.

\section{Reduced SP cell fraction after parthenolide treatment}

To investigate whether or not parthenolide has an effect on cancer stem-like cells of NPC cells, we examined the change in the SP percentage after treatment. As shown in Fig. 5A, the percentage of SP cells in CNE1 cells was reduced from $1.44 \%$ in control cells to $0.91 \%, 0.19 \%$, and $0.00 \%$ after treatment with 10,20 , and $30 \mu \mathrm{M}$ parthenolide (PN), respectively. Similarly, the percentage of SP cells in CNE2 cells was reduced from $3.12 \%$ in control cells to $1.34 \%, 0.41 \%$, and $0.30 \%$ after treatment with 10,20 , and $30 \mu \mathrm{M}$ parthenolide (PN), respectively (Fig. 5B). With respect to the time dependence of this effect, treatment with 5 $\mu \mathrm{M}$ parthenolide for $24 \mathrm{~h}, 48 \mathrm{~h}$, and $72 \mathrm{~h}$ decreased the percentage of SP cells in CNE2 cells from $3.43 \%$ in control cells to $3.02 \%, 2.86 \%$, and $0.49 \%$, respectively (Fig. 5C). The time- and concentration-dependent decrease in the SP cell fraction demonstrated that cancer stem-like cells in NPC are more sensitive to inhibition mediated by parthenolide. 
A

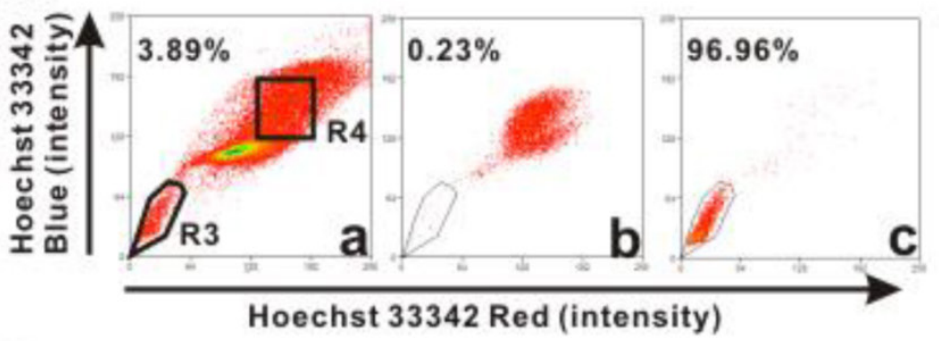

B
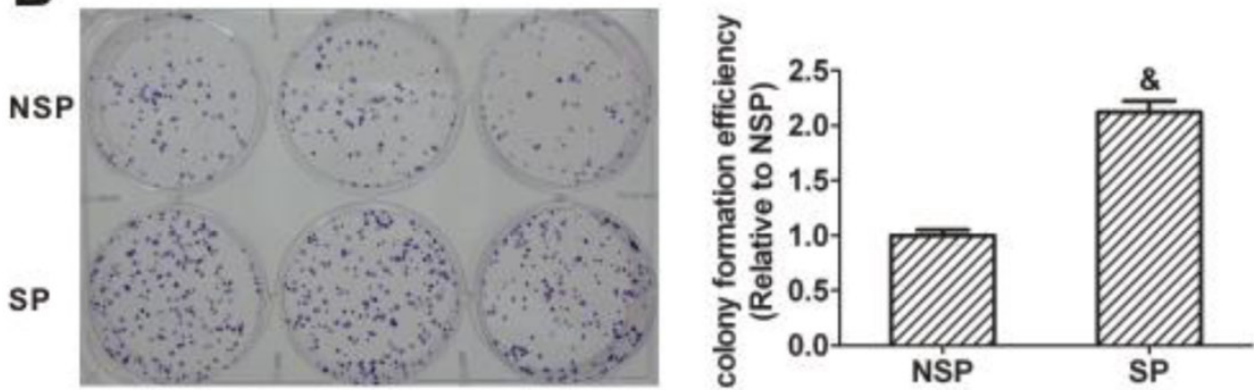

C

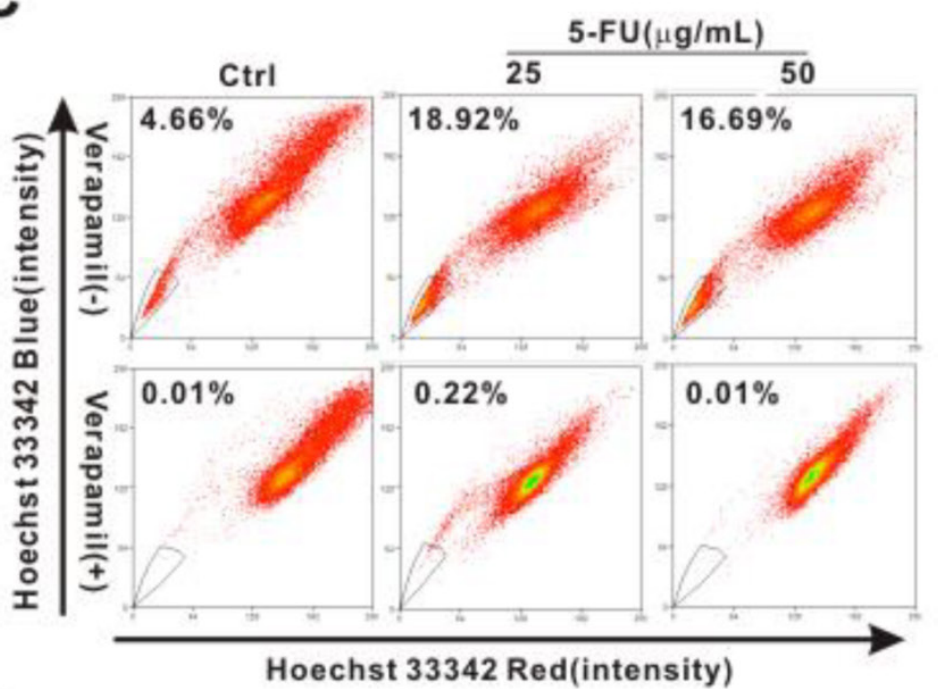

D

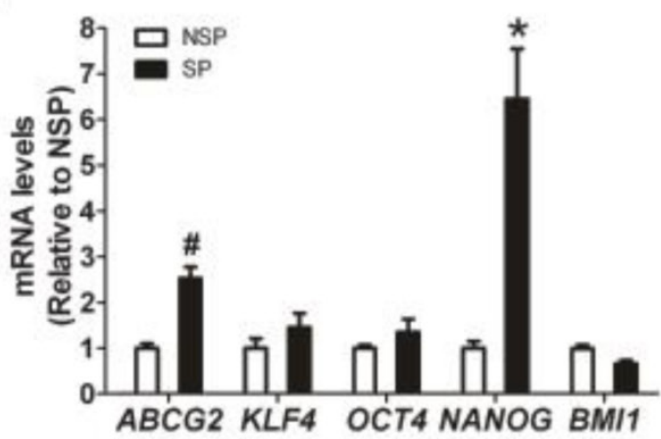

Figure 2. Cancer stem cell (CSC) characteristics of sorted side population (SP) cells. (A) SP cells were sorted from CNE2 cells by flow cytometry using Hoechst 33342 staining. The R3 gate showed the SP cells that were Hoechst 33342 negative/dim, and the R4 gate indicated the non-side population (NSP) cells that were Hoechst 33342 positive (Fig. 2A, panel a). The purity of NSP cells was $99.77 \%$ (panel b) and the purity of SP cells was $96.96 \%$ (panel c). The SP and NSP cells were collected for subsequent studies. (B) The colony formation assay showed more cell colonies and greater efficiency with SP cells than with NSP cells. And the relative colony formation efficiency (CFE) of SP cells was significantly higher than that of NSP cells $(\& P<0.001)$. The data shown are the means \pm SD of three parallel samples. (C) Flow cytometry analysis of the CNE2 cells treated with 5 -fluorouracil $(5-\mathrm{FU}, 25$ and $50 \mu \mathrm{g} / \mathrm{mL})$ for $24 \mathrm{~h}$. The SP was gated and shown as a percentage of the total cell population. The SP cells in CNE2 cells were increased by treatment with 5-FU (upper row). The SP phenotype was controlled by treatment with verapamil (lower row). A representative example of the SP proportion is displayed. The percentages of SP cells are indicated in the upper left-hand corners of the panels. (D) qRT-PCR assays of mRNA transcripts in NSP and SP cells. The ABCG2 and stemness-associated gene NANOG mRNA levels in SP cells were significantly higher than in NSP cells. The target gene expression was normalized to that of beta actin (ACTB). The data shown are the means \pm SD of three experiments for each group. $* P<0.05$ and $\# P<0.01$ compared with NSP cells; the data were analyzed by the $t$-test. 
A

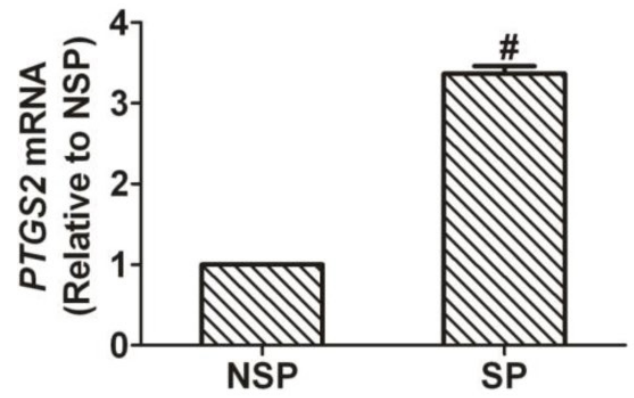

B

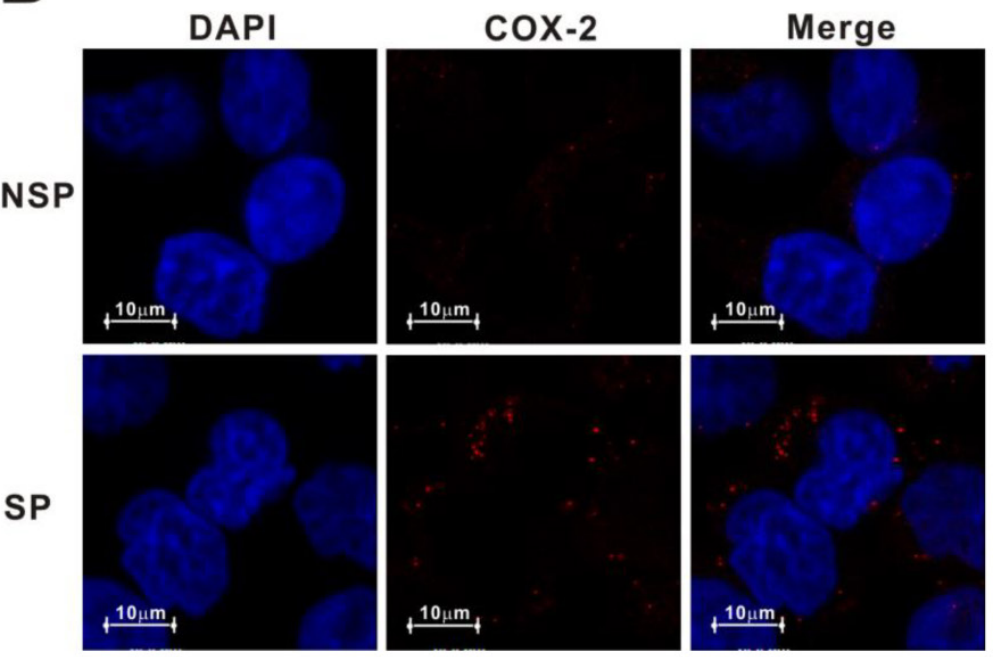

Figure 3. Upregulation of cyclooxygenase-2 (COX-2) in side population (SP) cells sorted from CNE2 cells. (A) Quantitative real-time polymerase chain reaction (qRT-PCR) assays for the mRNA levels of the prostaglandin-endoperoxide synthase 2 (PTGS2) gene, encoding COX-2 protein. The PTGS2 mRNA level in the SP cells sorted from CNE2 cells was significantly higher than in the non-side population (NSP) cells (\#P<0.01, $t$-test). The target gene expression was normalized to that of beta actin (ACTB). The data shown are the means \pm SD of three experiments for each group. (B) Immunofluorescence staining revealed that the expression of COX-2 protein was greater in SP cells than in NSP cells sorted from CNE2 cells.

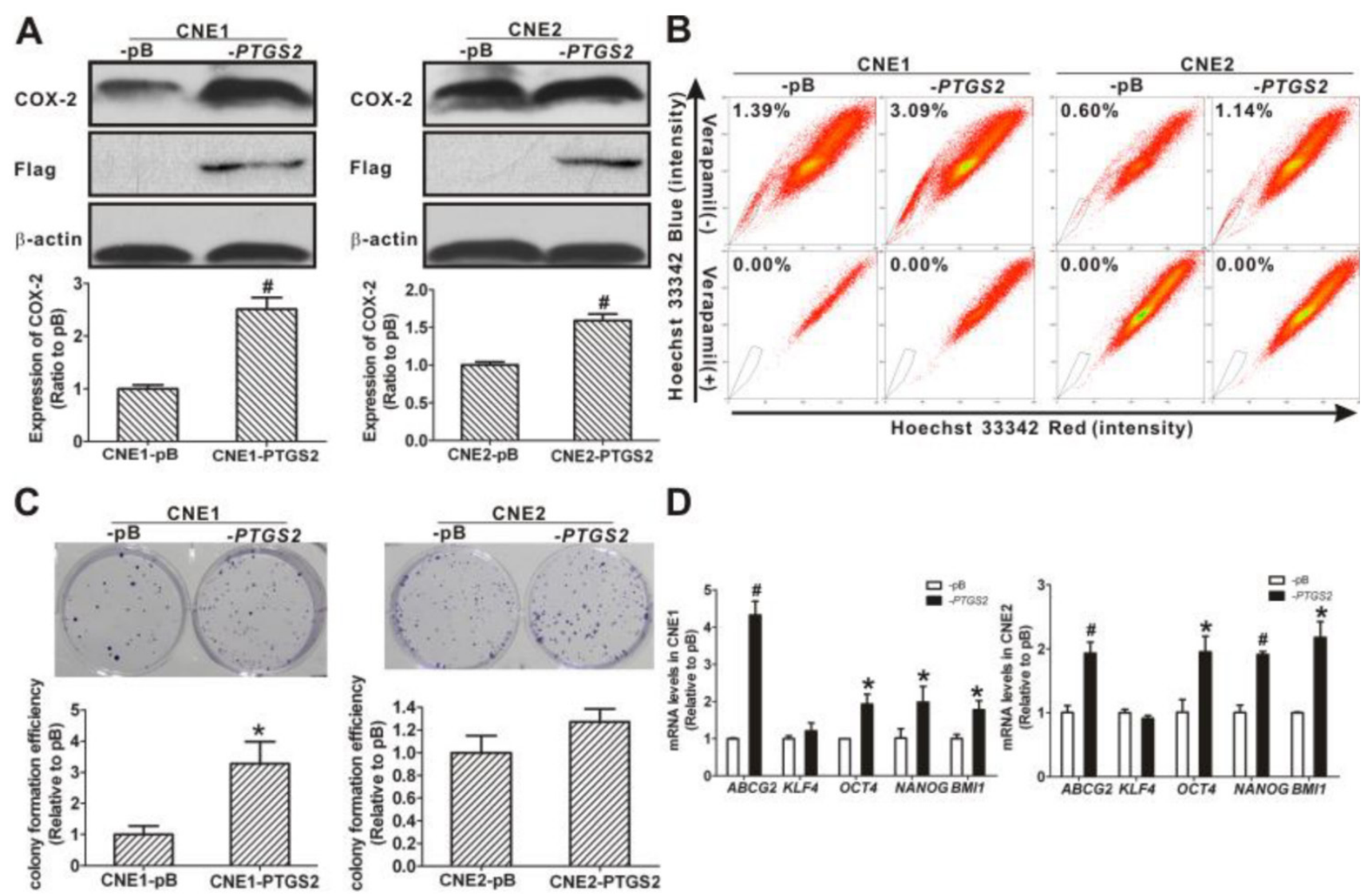

Figure 4. Changes of side population (SP) phenotype in nasopharyngeal carcinoma (NPC) cells resulting from overexpression of cyclooxygenase-2 (COX-2). (A) COX-2-overexpressing NPC cells were constructed by introducing the pBabe-PTGS2-FLAG recombinant plasmid or the pBabe-puro empty vector (as control) into CNE1 and CNE2 cells. Western blot analysis showed significantly higher flag-tagged COX-2 protein expression in CNE1-PTGS2 cells (left) and CNE2-PTGS2 cells (right) than in either control (-pB) cell line. $\beta$-Actin is shown as a loading control. The data shown are the means \pm SD of two independent assays. (B) Flow cytometry analysis of the SP cells in COX-2-overexpressing NPC cells. The SP was gated and shown as a percentage of the total cell population. The ratios of SP cells in both CNE1-PTGS2 and CNE2-PTGS2 cells were increased compared with corresponding control (-pB) cells (upper row). The SP phenotype was controlled by treatment with verapamil (lower row). A representative example of the SP proportion is displayed. The percentages of SP cells are indicated in the upper left-hand corners of the panels. (C) The colony formation assay showed that the number of cell colonies was increased in CNE1-PTGS2 cells (left). In CNE2-PTGS2 cells, the number of colonies did not increase when compared with -pB cells, but the cell colony area was significantly larger than in -pB cells (right). The data shown are the means \pm SD of three parallel samples. (D) qRT-PCR assays of the mRNA levels of $A B C G 2$ and stemness-associated genes in COX-2-overexpressing NPC cells. The ABCG2, OCT4, NANOG, and BMIl mRNA levels in both CNE1-PTGS2 (left) and CNE2-PTGS2 (right) cells were significantly higher than in corresponding control $(-\mathrm{pB})$ cells. The target gene expression was normalized to that of beta actin (ACTB). The data shown are the means \pm SD of three experiments for each group. $* P<0.05$ and $\# P<0.01$ compared with the control $(-\mathrm{pB})$ cells; the data were analyzed by the $t$-test. 
$\mathbf{A}_{\mathrm{CNE} 1}$

$\mathbf{P N}(\mu \mathrm{M})$

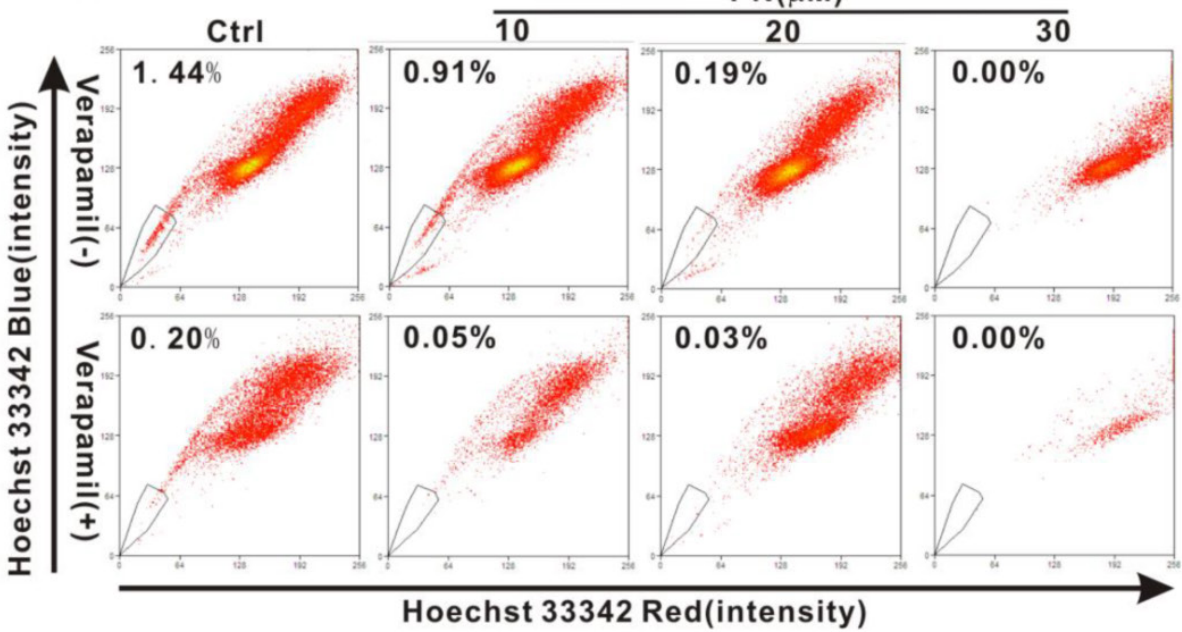

B

CNE2

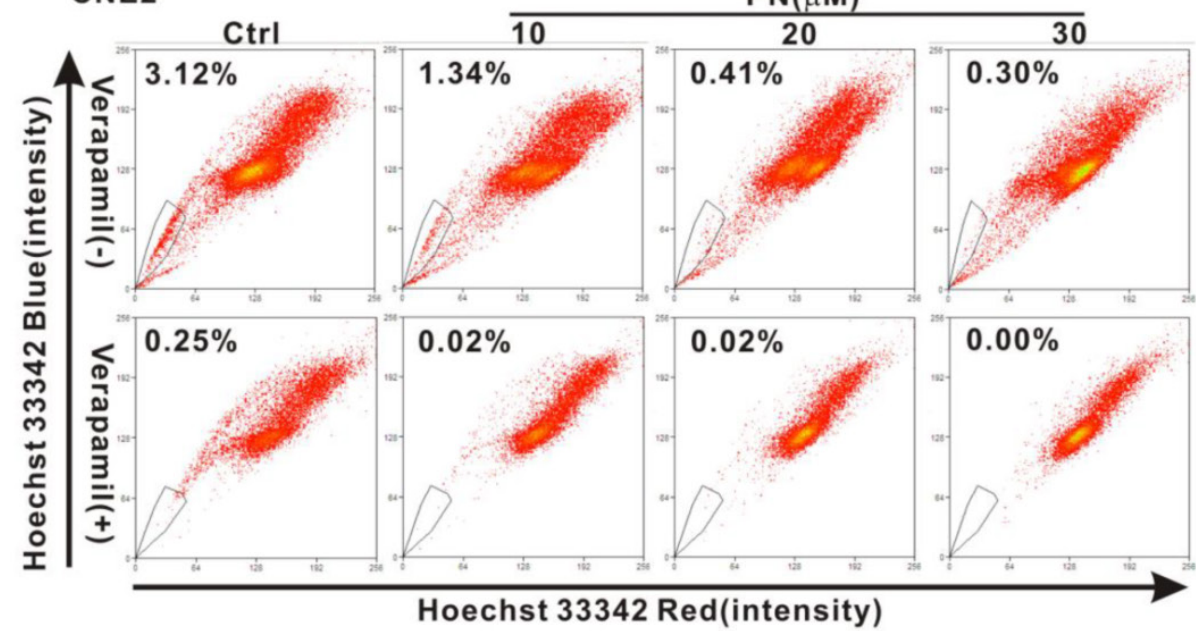

C CNE2

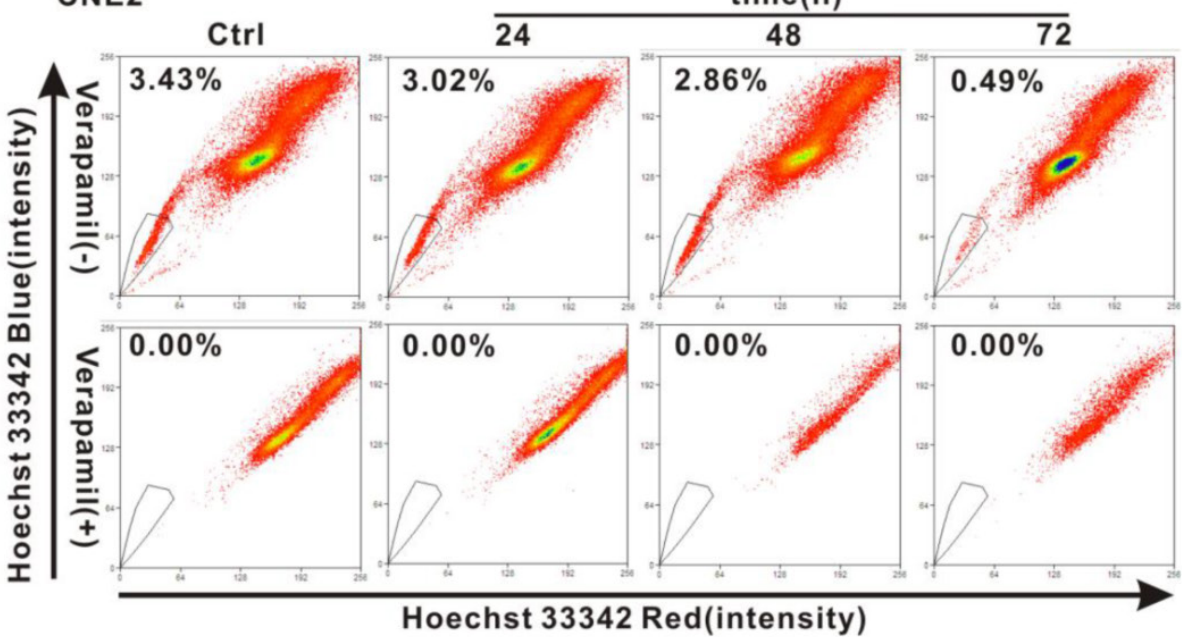

Figure 5. Parthenolide-induced inhibition of side population (SP) cells in nasopharyngeal carcinoma (NPC) cells. (A, B) The proportion of SP cells in CNE1 (A) and CNE2 cells (B) was counted by flow cytometry after treatment with parthenolide (PN, 10, 20, or $30 \mu$ M) for 24 h (upper row). (C) Flow cytometry analysis of CNE2 cells treated by parthenolide $(5 \mu \mathrm{M})$ for the indicated times $(24,48$, or $72 \mathrm{~h}$ ) (upper row). The SP was gated and shown as a percentage of the total cell population. The three parts of the figure showed that the fractions of SP cells in CNE1 and CNE2 cells decreased after treatment with parthenolide in a dose- and time-dependent manner (A-C). The SP phenotype was controlled by treatment with verapamil (lower rows in each part). A representative example of the SP proportion is displayed. The percentages of SP cells are indicated in the upper left-hand corners of the panels. 


\section{Inhibition of NPC cell proliferation and self-renewal ability of SP cells by parthenolide}

Next, MTT and cell colony formation assays were applied to determine whether parthenolide inhibits the proliferation of NPC cells and self-renewal ability of SP cells. As shown in Fig. 6A, parthenolide significantly reduced the growth of NPC cells in a dose-dependent manner $(P<0.01)$. Parthenolide had a stronger inhibitory effect on CNE1 cells than on CNE2 cells $(P<0.05)$ when cells were exposed to different concentrations $(1-100 \mu \mathrm{M})$. The $\mathrm{IC}_{50}$ values were 20.05 $\mu \mathrm{M}(95 \% \mathrm{IC}=16.24-24.55 \mu \mathrm{M})$ and $7.46 \mu \mathrm{M}(95 \% \mathrm{IC}=$ 5.68-9.62 $\mu \mathrm{M})$ for CNE1 cells, and $32.66 \mu \mathrm{M}(95 \% \mathrm{IC}=$ 29.70-35.73 $\mu \mathrm{M})$ and $10.47 \mu \mathrm{M}(95 \%$ IC $=7.77-13.84$ $\mu \mathrm{M})$ for CNE2 cells treated with parthenolide for 24 and $48 \mathrm{~h}$ (Fig. 6A), respectively. It was shown that the inhibitory effect of treatment with 0.625 to $10 \mu \mathrm{g} / \mathrm{mL}$ 5 -FU for $24 \mathrm{~h}$ plateaued at less than $40 \%$ in CNE1 and CNE2 cells (Fig. 6B), while parthenolide caused greater than $80 \%$ inhibition at a similar time $(24 \mathrm{~h})$ and concentration (1-80 $\mu \mathrm{M})$. In addition, with prolonged treatment time $(48 \mathrm{~h})$, the inhibition rate approached to $100 \%$ for 60 to $100 \mu \mathrm{M}$ parthenolide but less than $75 \%$ for 5-FU at a similar concentration in CNE1 and CNE2 cells. These results indicated that there is a $20 \%$ fraction of CNE1 and CNE2 cells that is resistant to 5-FU but is more sensitive to parthenolide (Fig. 6A, 6B). Moreover, the cell colony formation of NPC cells was also significantly inhibited by treatment with parthenolide (Fig. 6C). The effect of parthenolide on SP cells sorted from CNE2 cells was further evaluated through a colony formation assay. As shown in Fig. $6 \mathrm{D}$, SP cells were treated with lower doses of parthenolide $(1$ or $5 \mu \mathrm{M})$ and parthenolide significantly inhibited the cell colony formation of SP cells as expected, indicating that parthenolide decreases the self-renewal and differentiation abilities of SP cells.

\section{Inhibition of COX-2 expression by parthenolide}

Our data have demonstrated that COX-2 is overexpressed in SP cells compared with NSP cells (Fig. 3) and that overexpression of COX-2 increases NPC cancer stem-like cells phenotype (Fig. 4), implying that COX-2 plays a role in cancer stemness. To assess whether the underlying mechanism of targeting COX-2 makes cancer stem-like cells vulnerable to parthenolide, we first examined and compared COX-2 expression in CNE1 and CNE2 cells in response to a parthenolide challenge. After $24 \mathrm{~h}$ of treatment with 10,20 , or $30 \mu \mathrm{M}$ parthenolide, the COX-2 levels were decreased to $50.1 \pm 33.7 \%, 38.7 \pm 24.5 \%$, and $23.1 \pm$ $14.0 \%$ in CNE1 cells, and to $94.2 \pm 2.0 \%, 58.6 \pm 1.0 \%$, and $42.2 \pm 9.0 \%$ in CNE2 cells, respectively (Fig. 7A). Treatment with $10 \mu \mathrm{M}$ parthenolide for $24 \mathrm{~h}, 48 \mathrm{~h}$, or $72 \mathrm{~h}$ decreased the COX-2 level in CNE1 cells to $82.8 \pm$ $18.1 \%, 30.7 \pm 4.2 \%$, and $21.6 \pm 2.3 \%$, and in CNE2 cells to $87.3 \pm 10.3 \%, 77.7 \pm 15.1 \%$, and $35.5 \pm 10.6 \%$, respectively (Fig. 7B). Our results suggested that there was a time- and concentration-dependent decrease in COX-2 in response to parthenolide treatment. For comparative purposes, we also tested whether COX-2 expression is regulated by 5 -FU. In contrast to the results with parthenolide, the COX-2 levels increased in CNE1 and CNE2 cells treated with $25 \mu \mathrm{g} / \mathrm{mL}$ 5-FU for $24 \mathrm{~h}$ (Fig. 7C), indicating that parthenolide and 5 -FU play different roles on COX-2 regulation.

The inhibitory effect on COX-2 of parthenolide was also observed at the gene transcription level. As determined by qRT-PCR, parthenolide caused a concentration- and time-dependent decrease in PTGS2 mRNA (Fig. 8). Treatment with 10,20 , or $30 \mu \mathrm{M}$ parthenolide for $2 \mathrm{~h}$ decreased the level of PTGS2 mRNA to $50.3 \pm 11.6 \%, 31.1 \pm 1.9 \%$, and $26.7 \pm 4.5 \%$ of control in CNE1 cells, and to $67.5 \pm 6.2 \%, 78.0 \pm 14.8 \%$, and $44.4 \pm 11.8 \%$ of control in CNE2 cells, respectively (Fig. 8A). And treatment with $10 \mu \mathrm{M}$ parthenolide for $2 \mathrm{~h}$ and $4 \mathrm{~h}$ decreased the level of PTGS2 mRNA to $42.6 \pm 11.0 \%$ and $15.7 \pm 2.7 \%$ of control in CNE1 cells, and to $90.6 \pm 5.6 \%$ and $55.9 \pm 7.2 \%$ of control in CNE2 cells, respectively (Fig. 8B). These results suggested that the decrease of COX-2 protein levels shown in Figs. 7A and 7B may be at least partially due to parthenolide-induced suppression of PTGS2 transcription.

\section{Reduction of SP cell fraction and colony formation by selective COX-2 inhibitors}

Two selective COX-2 inhibitors, NS-398 and CAY10404 [39, 40], were used to further confirm that suppressing COX-2 causes the inhibition of cancer stem-like cells. As with parthenolide, NS-398 and CAY10404 significantly decreased COX-2 protein levels in CNE1 and CNE2 cells (Fig. 9A) and reduced the proportion of SP cells (Fig. 9B). Treatment with 5 or 10 $\mu \mathrm{M}$ NS-398 for $24 \mathrm{~h}$ decreased the fraction of SP cells in the CNE2 cells to $94.90 \%$ and $54.29 \%$ of control cells, respectively. A similar decrease in the fraction of SP cells (to $59.40 \%$ of control cells) was also observed following CAY10404 treatment (Fig. 9B). In addition, the cell colony formation of SP cells from CNE2 cells was significantly inhibited by the COX-2 inhibitors (Fig. 9C). These data demonstrated that COX-2 inhibition may reduce cancer stem-like SP cells and their self-renewal abilities in NPC. 
A

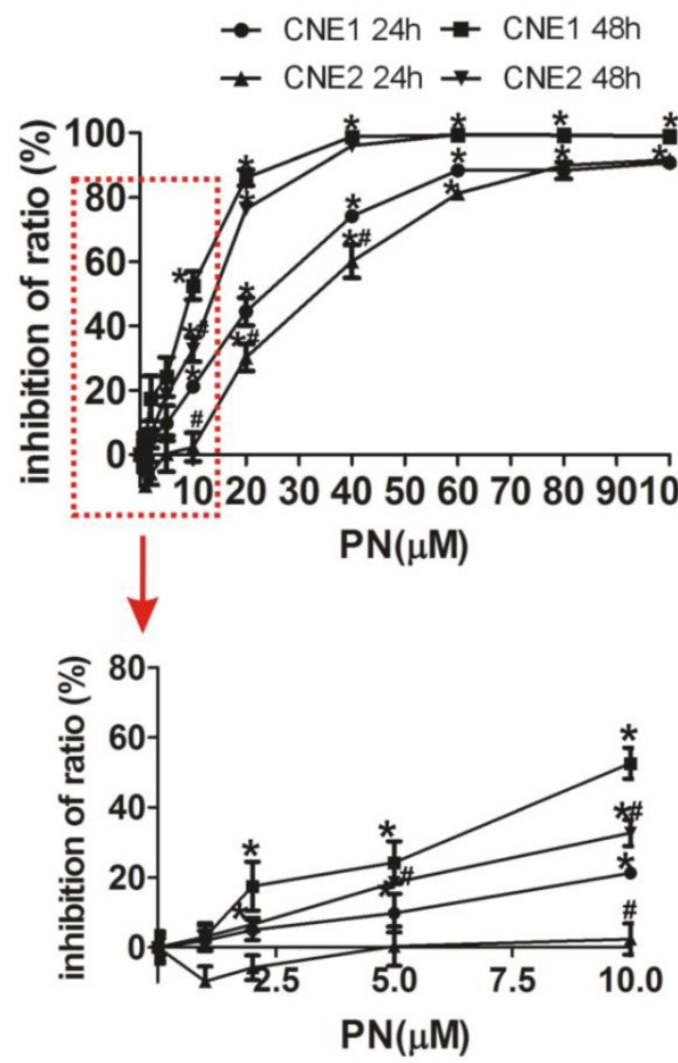

C

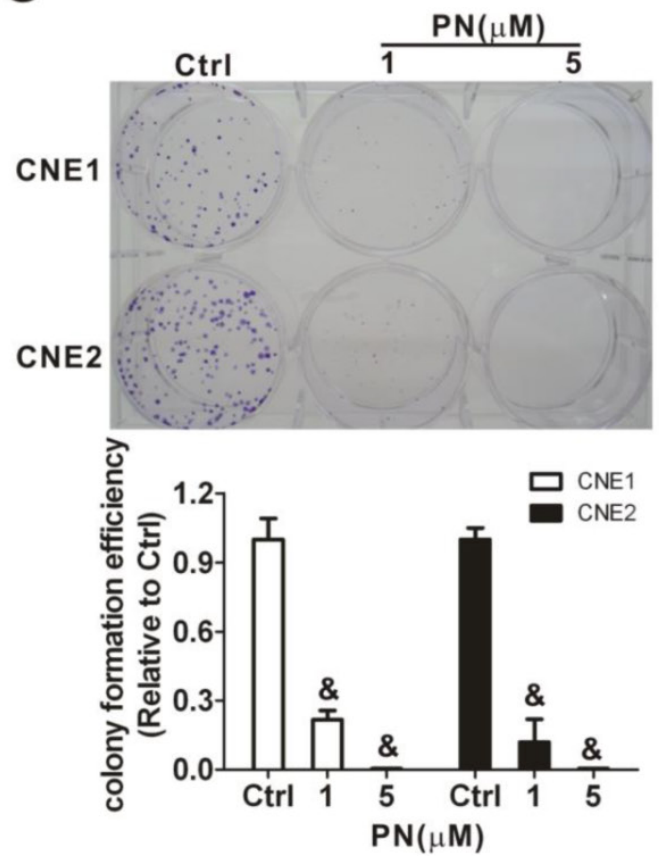

B

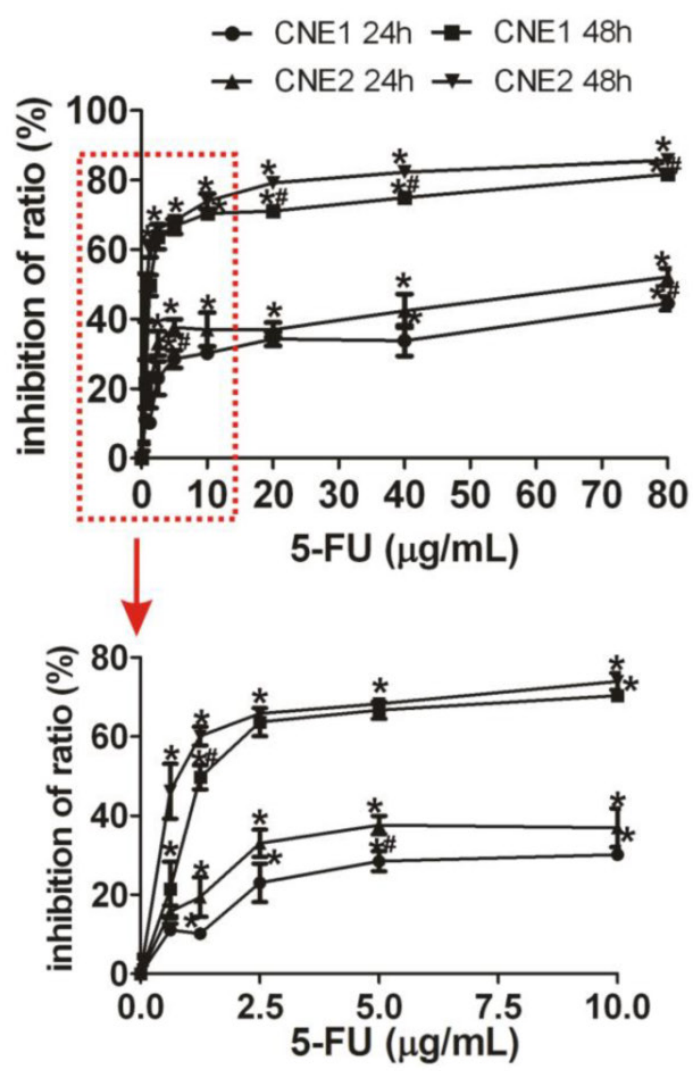

D
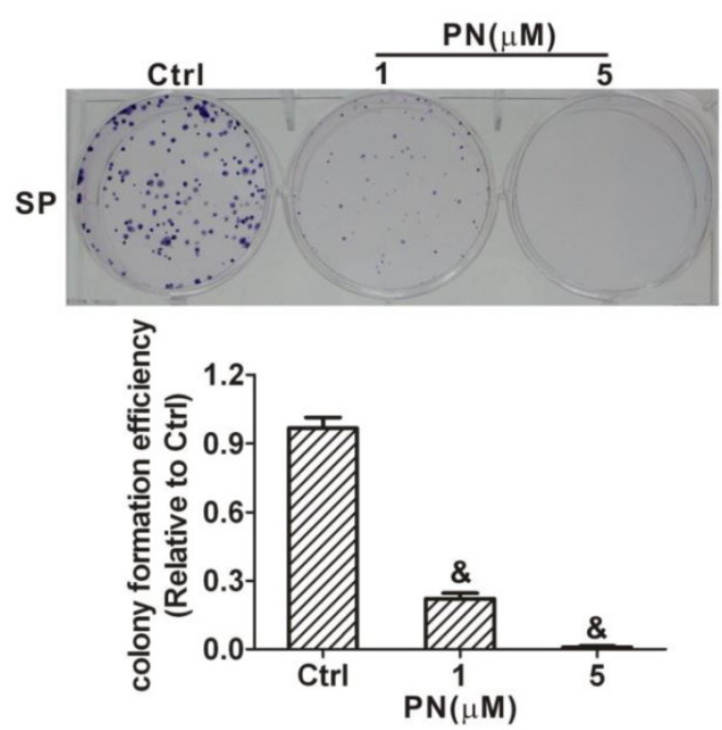

Figure 6. Inhibition of the cell proliferation and self-renewal ability of side population (SP) cells in nasopharyngeal carcinoma (NPC) cells treated with parthenolide. (A) Cell proliferation of CNE1 and CNE2 cells after treatment with parthenolide (PN, 1-100 $\mu \mathrm{M}$ ) for $24 \mathrm{~h}$ or $48 \mathrm{~h}$. The lower graphs, corresponding to the red rectangles in the upper graphs, showed the cell proliferation of NPC cells treated by parthenolide (PN) at 1-10 $\mu$ M. Parthenolide significantly inhibited the proliferation of NPC cells $(P<0.01)$. The points indicate the means of triplicate samples, and the bars represent the SD. $* P<0.05$ compared with the untreated group; $\# P<0.05$ compared with $C N E 1$ cells treated with the same dose of parthenolide (PN); the data were analyzed by the $t$-test. (B) Cell proliferation of CNE1 and CNE2 cells after treatment with 5 -fluorouracil $(5-\mathrm{FU}, 0.625-80 \mu \mathrm{g} / \mathrm{mL})$ for $24 \mathrm{~h}$ or $48 \mathrm{~h}$. The red rectangle showed the cell proliferation of NPC cells treated by $5-\mathrm{FU}$ at $0.625-5 \mu \mathrm{g} / \mathrm{mL}$. The points indicate the means of triplicate samples, and the bars represent the SD. $* P<0.05$ compared with the untreated group; $P<0.05$ compared with CNE1 cells treated with the same dose of 5-FU; the data were analyzed by the $t$-test. (C, D) The colony formation assays showed that the numbers of cell colonies in the CNE1 (Upper photographs) and CNE2 (Lower photographs) cells (C) and in the SP cells sorted from CNE2 cells (D) decreased after treatment with parthenolide (PN, 1 or $5 \mu M)$. The data shown are the means \pm SD of three parallel samples; \& $P<0.001$ compared with the control group (Ctrl); the data were analyzed by Dunnett's $t$-test. 
A
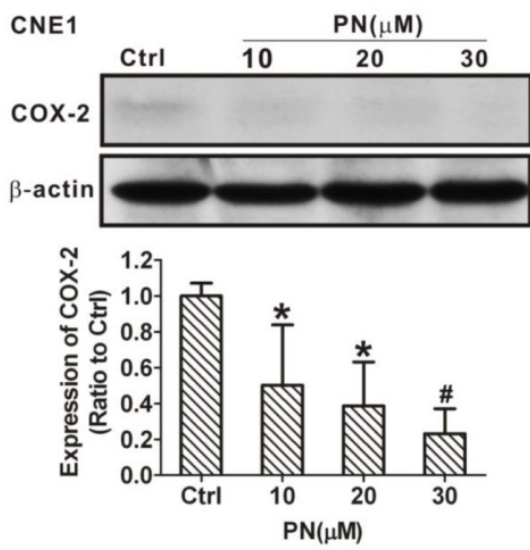

B
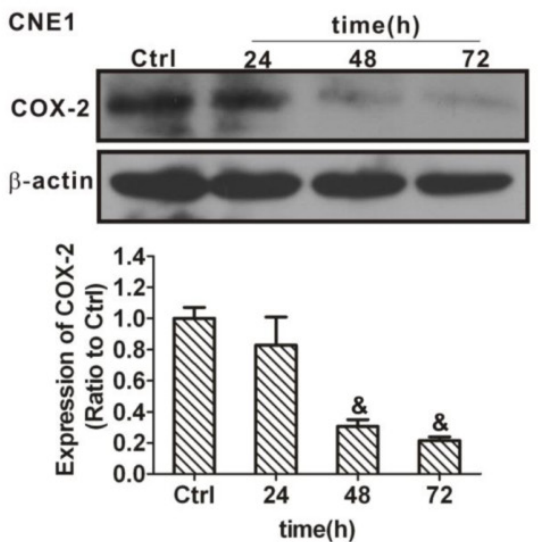

C

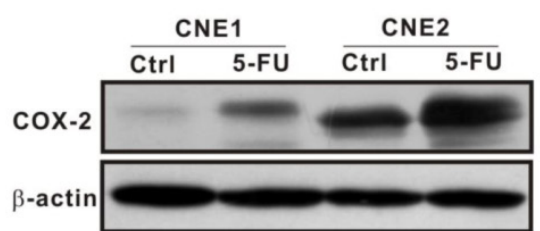

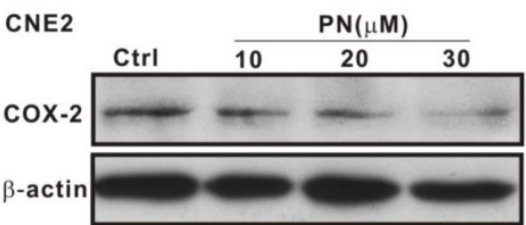
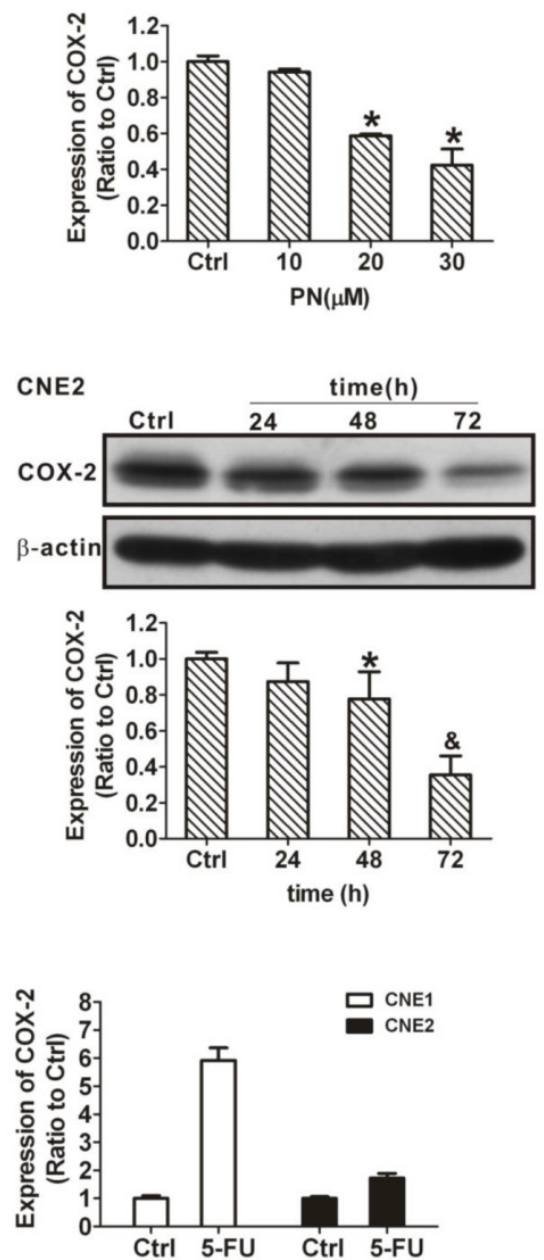

Figure 7. Inhibition of the expression of cyclooxygenase-2 (COX-2) in nasopharyngeal carcinoma (NPC) cells treated with parthenolide. (A) Western blot analysis of CNE1 (left) and CNE2 (right) cells after treatment with parthenolide (PN, 10, 20, or $30 \mu \mathrm{M})$ for 24 h. The expression of COX-2 decreased in a concentration-dependent manner after treatment with parthenolide for $24 \mathrm{~h}$. (B) CNE1 (left) and CNE2 (right) cells were subjected to COX-2 level analysis after treatment with parthenolide $(10 \mu \mathrm{M})$ for the indicated times $(24,48$, or $72 \mathrm{~h})$. The expression of COX-2 decreased in a time-dependent manner after treatment with parthenolide. (C) Western blot assays showed that the expression of COX-2 in CNE1 and CNE2 cells was induced by treatment with 5 -fluorouracil (5-FU, $25 \mu \mathrm{g} / \mathrm{L})$ for $24 \mathrm{~h}$. The image shown is of a representative experiment. $\beta$-Actin is used as the loading control. The data shown are the means $\pm S D$ of two independent assays. $* P<0.05$, $\# P<0.01$, and \& $P<0.001$ compared with the control group (Ctrl); the data were analyzed by Dunnett's $t$-test.
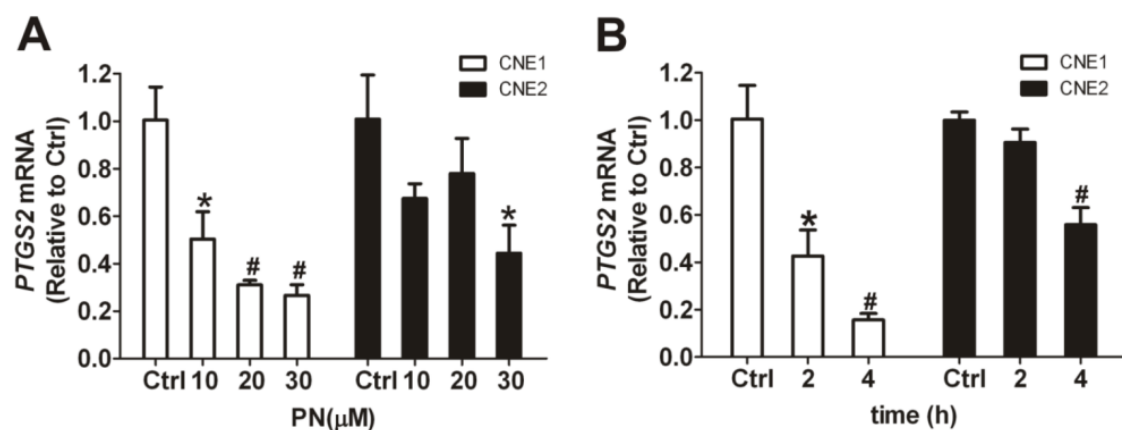

Figure 8. Downregulation, induced by parthenolide, of prostaglandin-endoperoxide synthase 2 (PTGS2) mRNA in nasopharyngeal carcinoma (NPC) cells. (A) qRT-PCR assay of PTGS2 mRNA in CNE1 cells and CNE2 cells treated with parthenolide (PN, 10, 20, or $30 \mu \mathrm{M})$ for 2 h. Parthenolide downregulated the level of PTGS2 mRNA in a concentration-dependent manner. (B) PTGS2 mRNA level in CNE1 cells and CNE2 cells after treatment with parthenolide (10 $\mu M)$ for the indicated times $(2$ or $4 \mathrm{~h})$. Parthenolide decreased the PTGS2 mRNA level in a time-dependent manner. The target gene expression was normalized to the level of beta actin (ACTB). The data shown are the means $\pm S D$ of three independent assays. $* P<0.05$ and $\# P<0.01$ compared with the control group (Ctrl); the data were analyzed by Dunnett's $t$-test. 
$\mathrm{ANE1}_{\mathrm{CNE}}$
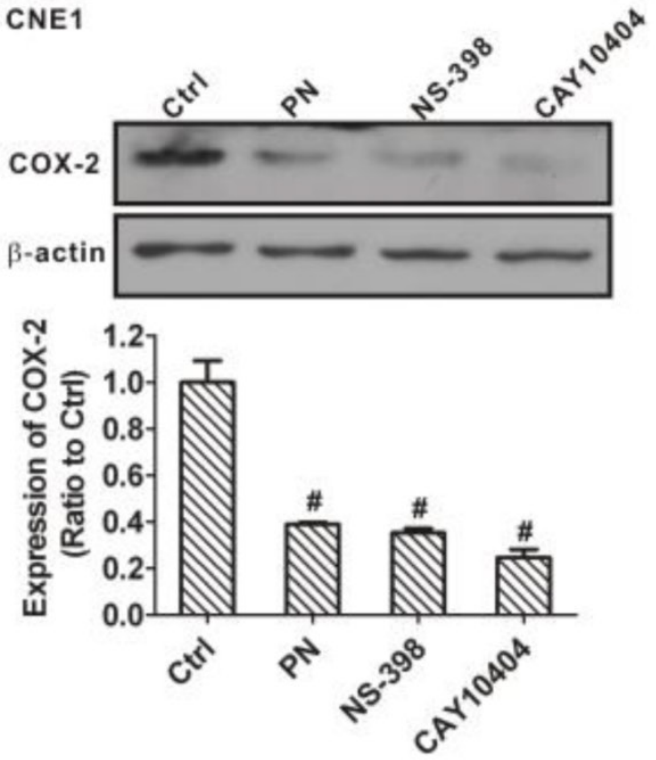

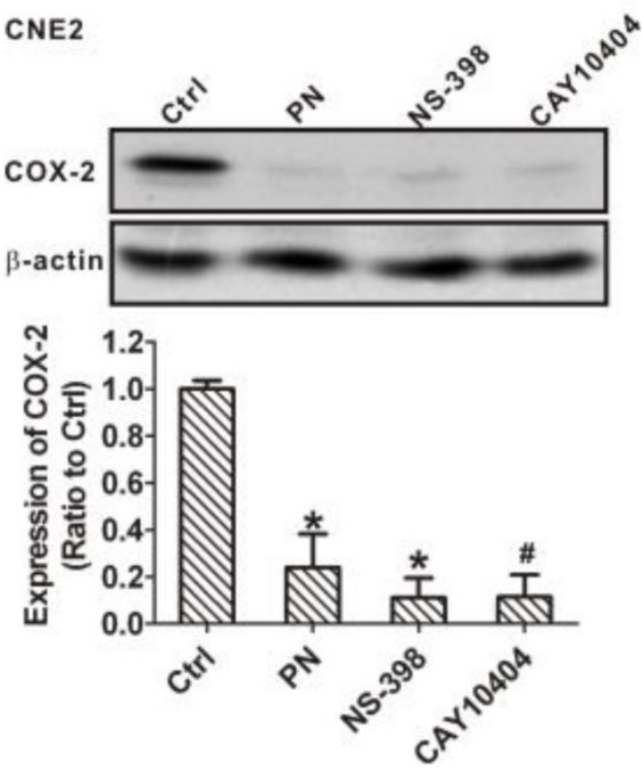

B

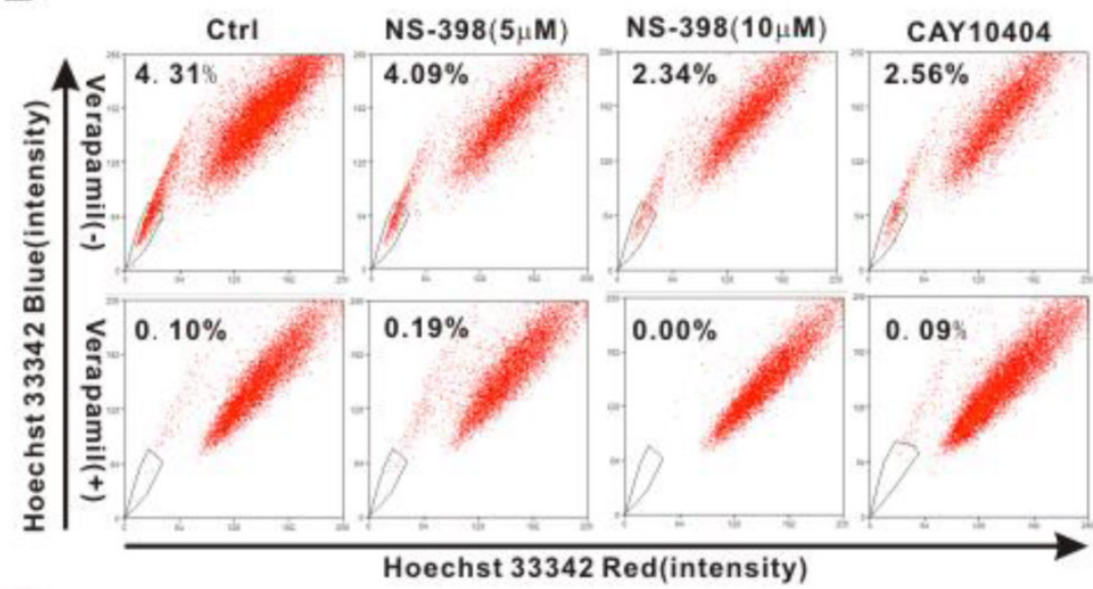

C

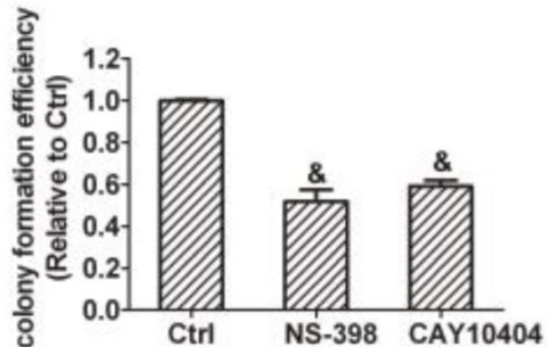

Figure 9. Downregulation of side population (SP) cells and their self-renewal ability by selective cyclooxygenase-2 (COX-2) inhibitors. (A) Western blot analysis of COX-2 levels in CNE1 (left) and CNE2 (right) cells after treatment with dimethyl sulfoxide (DMSO, Ctrl), parthenolide (PN, $30 \mu M)$, NS-398 (20 $\mu$ M), or CAY10404 $(20 \mu \mathrm{M})$ for $24 \mathrm{~h}$. COX-2 inhibitors NS-398 and CAY10404, similar to parthenolide, significantly decreased the expression of COX-2. $\beta$-Actin is used as a loading control. The image shown is of a representative of results. The data shown are the means \pm SD of two independent assays. (B) CNE2 cells were treated by DMSO (Ctrl), NS- 398 (5 and 10 $\mu \mathrm{M})$, or CAY10404 $(10 \mu \mathrm{M})$ for $24 \mathrm{~h}$. SP cells were analyzed by flow cytometry. The SP was gated and shown as a percentage of the total cell population. The proportion of SP cells decreased after treatment with these COX-2 inhibitors (upper row). The SP phenotype was controlled by treatment with verapamil (lower row). A representative example of the SP proportion is displayed. The percentages of SP cells are indicated in the upper left-hand corners of the panels. (C) The colony formation assay showed that the colony numbers and the relative colony formation efficiency of SP cells sorted from CNE2 cells were significantly decreased by treatment with NS-398 $(20 \mu \mathrm{M})$ or CAY10404 (10 $\mu$ M) for $72 \mathrm{~h}$. The data shown are the means \pm SD of three parallel samples. $* P<0.05, \# P<0.01$ and $\& P<0.001$ compared with the vehicle group (Ctrl); the data were analyzed by Dunnett's t-test. 


\section{Down-regulation of the SP phenotype in COX-2 knockdown cells}

To better understand the involvement of COX-2 in the cancer stemness, PTGS2 (COX-2) was knocked down using lentivirus-mediated PTGS2-shRNA. The COX-2 protein levels were decreased to $35.3 \pm 11.0 \%$ of control in CNE1-shPTGS2 cells and to $14.3 \pm 3.0 \%$ of control in CNE2-shPTGS2 cells (Fig. 10A). Compared to control cells, the percentage of SP cells decreased from $1.39 \%$ to $0.08 \%$ in CNE1-shPTGS2 cells and from $3.09 \%$ to $0.13 \%$ in CNE2-shPTGS2 cells, respectively (Fig. 10B). Knockdown of COX-2 also markedly reduced the cell colony formation efficiency of CNE1-shPTGS2 cells (Fig. 10C), while the area of cell colony in CNE2-shPTGS2 cells was smaller than that in control cells (data not shown). In addition, knockdown of COX-2 significantly downregulated the mRNA levels for ABCG2, OCT4, and BMI1 in CNE1-shPTGS2 cells and CNE2-shPTGS2 cells compared with the control cells $(P<0.01$, Fig. 10D). These data suggested a direct role of COX-2 in maintaining the cancer stemness characteristics in NPC cells.

\section{Maintenance of SP cell content by partial COX-2 expression}

To further validate the requirement for remaining COX-2 in maintaining SP in NPC, small-interfering RNA (siRNA, as opposed to the shRNA used in the previous section) was used to decrease the COX-2 expression slightly in CNE2 cells. As shown in Fig. 11A, the level of COX-2 protein in cells transfected with PTGS2-siRNA was $70.5 \pm 7.9 \%$ of control cells. Applying these partial COX-2 knockdown cells as a rescue assay, we demonstrated that the SP percentage decreased from $3.97 \%$ in the control to $2.15 \%$ (Fig. 11B), less of a change than that seen in CNE2-shPTGS2 cells (from $3.09 \%$ in control to $0.13 \%$, Fig. 10B), implying an essential role of COX-2 in SP cells.
A



C

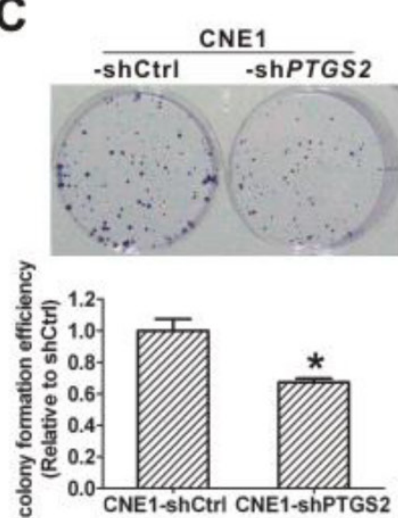

B
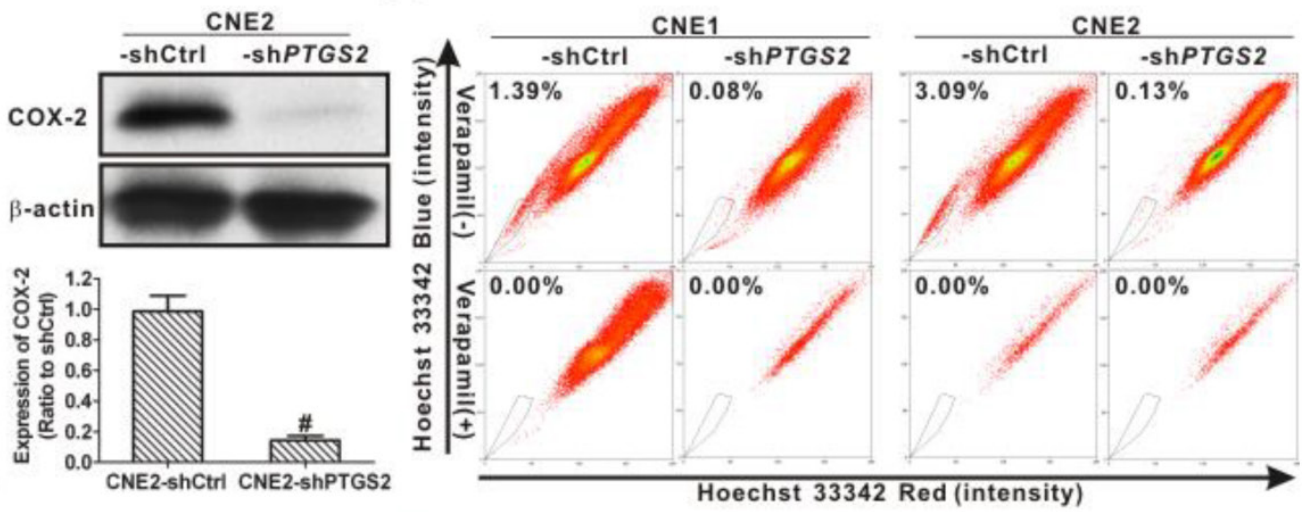

D


Figure 10. Inhibition of cancer stem cell (CSC) properties in nasopharyngeal carcinoma (NPC) cells caused by cyclooxygenase-2 (COX-2) knockdown. (A) CNE1 (left) and CNE2 (right) cells were transfected with control short hairpin RNA (shRNA), shCtrl or PTGS2-shRNA lentivirus. Western blot analysis showed that COX-2 protein was markedly reduced in both CNE1-shPTGS2 and CNE2-shPTGS2 cells compared with the corresponding shCtrl cells. $\beta$-Actin is shown as a loading control. The data shown are the means \pm SD of two independent assays. (B) Flow cytometry analysis showed that the percentage of side population (SP) cells was reduced in both CNE1-shPTGS2 and CNE2-shPTGS2 cells compared with the corresponding shCtrl cells (upper row). The SP phenotype was controlled by treatment with verapamil (lower row). The SP was gated and shown as a percentage of the total cell population. A representative example of the SP proportion is displayed. The percentages of SP cells are indicated in the upper left-hand corners of the panels. (C) The colony formation assay showed that the numbers of cell colonies in the CNE1-shPTGS2 cells (left) and the colony area of CNE2-shPTGS2 cells (right) decreased, when compared with the shCtrl cells. The data shown are the means \pm SD of three parallel samples. (D) $q R T-P C R$ assay for the mRNA levels of $A B C G 2$ and stemness-associated genes in CNE1-shPTGS2 cells (left) and in CNE2-shPTGS2 cells (right). The target gene expression was normalized to that of beta actin (ACTB). The data shown are the means \pm SD of three experiments for each group. $* P<0.05$ and $\# P<0.01$ compared with the shCtrl; the data were analyzed by the $t$-test. 

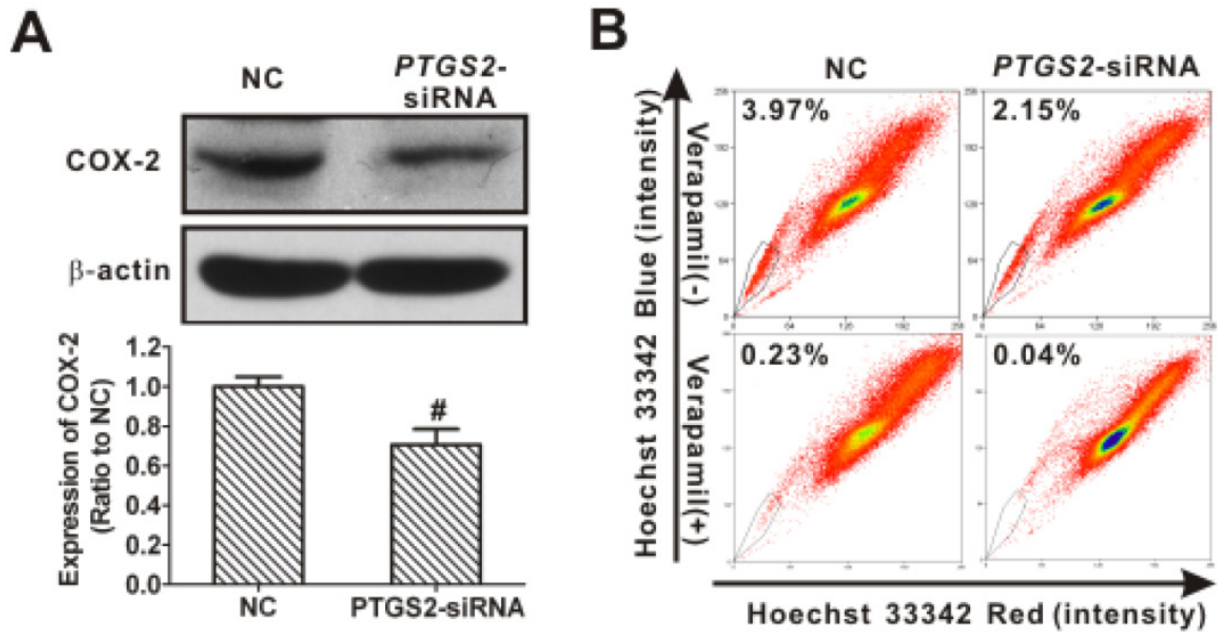

Figure 11. Restoration of side population (SP) cell content in nasopharyngeal carcinoma (NPC) cells resulting from partial cyclooxygenase-2 (COX-2) expression. (A) Western blot analysis showed that COX-2 protein was reduced to $70.5 \pm 7.9 \%$ of control in CNE2 cells transfected with PTGS2 small interfering RNA (siRNA) $(50 \mathrm{nM})$ for $48 \mathrm{~h}$, when compared with control siRNA (NC) cells. $\beta$-Actin is shown as a loading control. The data shown are the means \pm SD of two independent assays; \# $P<$ 0.01 compared with NC; the data were analyzed by $t$-test. (B) Flow cytometry was used to analyze the SP cells in CNE2 cells. The SP was gated and shown as a percentage of the total cell population. The proportion of SP cells was rescued from the slightly decreased level in COX-2-retaining cells transfected with PTGS2-siRNA (upper row). The SP phenotype was controlled by treatment with verapamil (lower row). A representative example of the SP proportion is displayed. The percentages of SP cells are indicated.

\section{Down-regulation of COX-2 expression by parthenolide via the inhibition of NF-KB activation}

NF- $\kappa B$ plays a vital role in the regulation of the PTGS2 gene [31]. Studies have shown that parthenolide may indirectly inhibit COX-2 transcription through the NF- $\mathrm{KB}$ pathway [41]. In this study, the role of the NF- $\mathrm{KB}$ signaling pathway in response to a parthenolide challenge was examined. As shown in Fig. 12A, the level of nuclear NF-kB p65 (p65) protein in CNE1 was significantly decreased after treatment with parthenolide or PDTC (an inhibitor of NF- $\mathrm{B}$, used as a positive control $)(P<0.01)$. Moreover, parthenolide inhibited the level of nuclear p65 induced by TNF- $\alpha$ (an activator of NF- $\kappa B$ ) in CNE1 and CNE2 cells. Meanwhile, parthenolide slightly suppressed the decrease of cytoplasm p65 induced by TNF- $\alpha$ (Fig. 12A). These data indicated that parthenolide inhibits NF-KB nuclear translocation and activation in NPC cells.

To identify the molecular targets of parthenolide in the NF-kB pathway, CNE1 and CNE2 cells were stimulated with TNF- $\alpha$ in the absence or presence of parthenolide or PDTC, and molecular markers of the NF- $\kappa B$ pathway were analyzed in parallel. The inhibitory effects of parthenolide on TNF- $\alpha$-induced I $\mathrm{I} B \alpha$ protein degradation and IKK activation were studied. As shown in Fig. 12B, parthenolide significantly inhibited phosphorylation of IKK $\alpha / \beta$ and IкB $\alpha$ induced by TNF- $\alpha$, while the total protein content of IKK $\alpha$ and IKK $\beta$ was not significantly affected by TNF- $\alpha$ or parthenolide. Moreover, parthenolide significantly prevented the IкB $\alpha$ degradation induced by TNF- $\alpha$. In addition, the treatment with parthenolide or PDTC suppressed the phosphorylation of p65 activated by TNF- $\alpha$ (Fig. 12B). Interestingly, the expression of COX-2 also decreased, to $38.3 \pm 2.4 \%$ or $83.0 \pm 2.8 \%$ of control after treatment with parthenolide or PDTC (Fig. 12C). These results indicated that parthenolide inhibition of the NF- $\kappa B$ signaling pathway may partly involve the repression of COX-2.

\section{Discussion}

The CSCs are not only critical in the initiation, development, metastasis, and recurrence of tumors, but they also play roles in the ineffectiveness of conventional cancer therapy [5-8]. Currently, the complete elimination of cancer continues to elude oncologists because $90 \%$ of drug failures in metastatic cancers are attributed to chemoresistance [42]. It had been reported that the classic chemotherapeutic agent 5-FU was able to eradicate the bulk of the tumor cells, but not the CSCs, which may make some tumors resistant to this drug $[42,43]$. The accepted underlying mechanism of drug resistance is that the cancer stem-like SP cells extrude chemotherapy drugs due to the overexpression of one or more $A B C$ transporters, including ABCG2 and ABCB1/multidrug resistance protein 1 (MDR1), making them inherently resistant to conventional chemotherapy and chemo-radiation therapies $[6,9]$. In the present study, in agreement with a previous report [10], we have found that the SP cells of NPC cells exhibit CSC-like properties, such as higher CFE, overexpression of stem cell-associated genes, and resistance to chemotherapy $[5,11]$. We used this cell model to study the mechanism of drug resistance related to CSCs in NPC. 


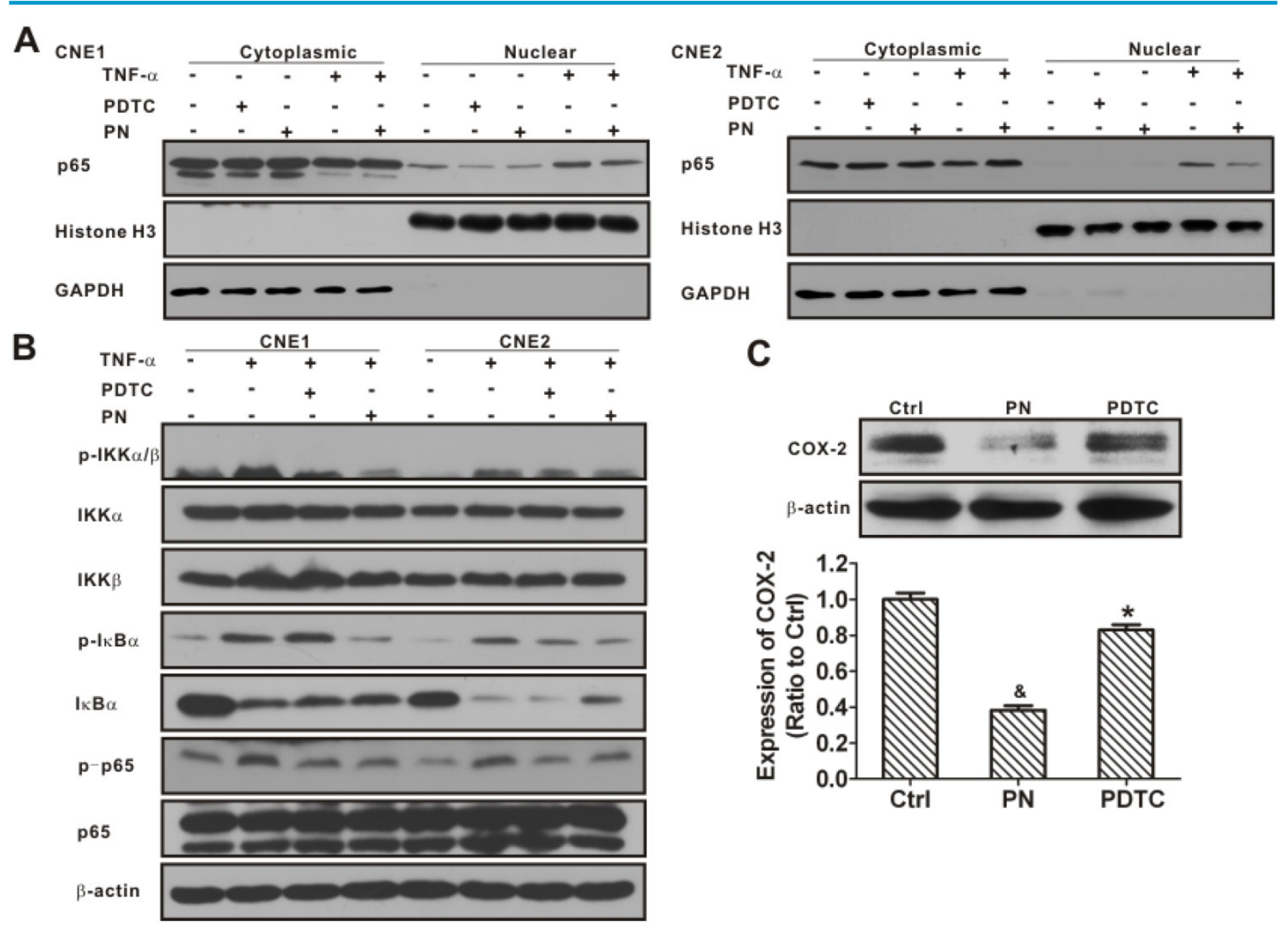

Figure 12. Inhibition of nuclear factor-KB (NF-KB) signaling activation and cyclooxygenase-2 (COX-2) expression in nasopharyngeal carcinoma (NPC) cells resulting from parthenolide exposure. (A) CNE1 (left) and CNE2 (right) cells were treated with parthenolide (PN, $30 \mu M)$ or pyrrolidine dithiocarbamate (PDTC, 30 $\mu \mathrm{M})$ for $4.5 \mathrm{~h}$, or treated with TNF- $\alpha(25 \mathrm{ng} / \mathrm{mL})$ for $30 \mathrm{~min}$, or treated with parthenolide $(30 \mu \mathrm{M})$ for $4 \mathrm{~h}$ prior to TNF- $\alpha$ exposure. The cytoplasmic and nuclear fractions were prepared and subjected to western blotting. The results showed that both PN and PDTC significantly inhibited the nuclear localization of NF- $\mathrm{B}$ p 65 in CNE1 and CNE2 cells. Glyceraldehyde 3-phosphate dehydrogenase (GAPDH) and histone $\mathrm{H} 3$ were used as controls for the cytoplasmic and nuclear protein fractions, respectively. (B) CNE1 and CNE2 cells were pre-treated with parthenolide (PN, $30 \mu \mathrm{M})$ or PDTC $(30 \mu \mathrm{M})$ up to 4 h before TNF- $\alpha$ treatment $(25 \mathrm{ng} / \mathrm{mL})$ for $30 \mathrm{~min}$. Western blot analysis showed that parthenolide inhibited the phosphorylation of IKK $\alpha / \beta, I \kappa B \alpha$, and NF- $\kappa B$ p 65 , and the degradation of I $\mathrm{B} \alpha$ induced by TNF- $\alpha$. (C) Western blot analysis of COX-2 in CNE2 cells after treatment with parthenolide $(30 \mu \mathrm{M})$ or PDTC $(30 \mu \mathrm{M})$ for $24 \mathrm{~h}$. Both parthenolide and PDTC significantly inhibited the expression of COX-2 in CNE2 cells $(P<0.05)$. $\beta$-Actin is used as a loading control. The image shown is of a representative experiment. The data shown are the means \pm SD of two independent assays. $* P<0.05$ and \& $P<0.001$ compared with the control group (Ctrl); the data were analyzed by Dunnett's $t$-test.

A previous population study had reported that increased COX-2 expression is associated with chemotherapy resistance [44]. Our data revealed that CNE2 cells, with higher COX-2 expression, had a higher SP cell content than CNE1 cells (Fig. 1). And higher levels of PTGS2 mRNA and COX-2 protein were found in the SP cells (Fig. 3), showing that COX-2 may play a pivotal role in CSC-like SP cells of NPC. Since it is known that CSCs are resistant to 5-FU, we treated NPC cells with 5-FU and found that 5-FU significantly increased the percentage of cancer stem-like SP cells (Fig. 2C) and also upregulated the expression of COX-2 (Fig. 7C), suggesting that COX-2 plays a key role in chemotherapy resistance in NPC. However, the link between COX-2 and resistance to chemotherapy remained unclear, so the role of COX-2 in drug resistance of CSCs was then explored.

In recent years, there has been an increasing in- terest in exploring the potential link between COX-2 and $A B C$ transporters in cancer [45], because $A B C$ transporters (such as Bcrp1/ABCG2), molecular determinants of the SP phenotype, have been reported to increase in a wide variety of stem cells [9], and COX-2 has a potential role in the regulation of $A B C$ transporters [46, 47]. In the present study, we found that the ABCG2 gene was significantly upregulated in CNE2 cells with high COX-2 protein levels compared to CNE1 cells. And CNE2 cells, compared to CNE1 cells, possessed stronger stem cell characteristics, including self-renewal ability (increased CFE) and higher transcription of stemness-related genes such as KLF4, OCT4, NANOG, and BMI1 (Fig. 1). These data suggest a correlation between $\mathrm{COX}-2$ expression and cancer stemness in NPC cells. Using a gain-of-function approach, we demonstrated that overexpressing COX-2 increased the SP proportion, 
CFEs, and mRNA levels of ABCG2 and stemness-associated genes in NPC cells (Fig. 4). In contrast, selective COX-2 inhibitors showed an inhibitory effect (Fig. 9). Moreover, the loss-of-function approach demonstrated that COX-2 plays an essential role in CSC maintenance. Genetic knockdown of COX-2 (64.7 $\%$ in CNE1 and $85.7 \%$ in CNE2) by shRNA caused a remarkable decrease in the SP content and cancer stemness properties (Fig. 10). On the other hand, partially suppressing (29.5\% in CNE2) COX-2 by siRNA caused a much lesser SP content inhibition (Fig. 11). The results indicated that COX-2 plays a vital role in cancer stem-like cell biology and may be a candidate biomarker for theranostics of NPC. Thus, the inhibition of COX-2 can be used as an effective strategy for targeting CSC-like cells.

Current treatments for NPC primarily target the more differentiated and rapidly proliferating tumor cells but have minimal cytotoxicity against CSCs. Recent studies indicated that parthenolide may target CSCs in various cancers, including leukemia and breast cancer [20]. In this study, we showed that compared to the standard chemotherapy drug 5-FU, parthenolide decreased the percentage of SP cells, and was more cytotoxic toward SP cells than toward NSP cells, indicating that parthenolide has more effect on the SP cells in a population of NPC cells. Moreover, treatment with parthenolide at lower doses could completely inhibit the self-renewal abilities in NPC cells, showing that parthenolide could preferentially target the cancer stem-like SP cells. These data suggested that parthenolide has an intriguing potential as an alternative treatment for NPC, particularly with regard to CSCs.

Parthenolide is known to be a potent inhibitor of $\mathrm{NF}-\kappa \mathrm{B}$, targeting multiple steps along the NF- $\kappa \mathrm{B}$ signaling pathway $[14,20,41]$. One study has reported that parthenolide inhibited the cell proliferation and colony formation of breast cancer stem-like SP cells by

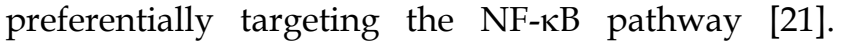
Studies have also demonstrated that parthenolide selectively affected leukemic stem cells through the NF- $\kappa B$ pathway, but not normal progenitor cells [17, 18 , 30]. It seems likely that the mechanism by which parthenolide selectively targets CSCs is associated with the inhibition of NF-kB in leukemia, bone, breast, mesenchyme tumors and prostate carcinoma [20]. One reason for this selectivity might be the higher NF- $\mathrm{BB}$-dependent survival in CSCs relative to normal stem cells [20, 29]. In agreement with this hypothesis, our experiment showed that parthenolide inhibited the phosphorylation of the IкB kinase (IKK) complex, prevented IкB $\alpha$ degradation, and resulted in the sustained cytoplasmic retention of NF- $\kappa \mathrm{B}$, thereby inhibiting its nuclear translocation and transcriptional ac- tivity. Thus, inhibition of the NF- $\kappa B$ pathway may be the underlying mechanism for parthenolide in preferentially targeting cancer stem-like SP cells of NPC.

Genetic studies using a dominant-negative repressor of NF- $\mathrm{KB}$ have shown that the inhibition of $\mathrm{NF}-\kappa \mathrm{B}$ alone is not sufficient to mediate the cell death observed with parthenolide, suggesting an involvement of multiple molecules $[17,48]$. It has been reported previously that a COX-2 selective inhibitor suppressed the growth of cancer stem-like cells from glioblastoma [34]. Interestingly, in the current study, besides NF-kB, COX-2 was also downregulated by parthenolide. A rapid downregulation of PTGS2 mRNA (Fig. 8) and COX-2 protein (Fig. 7) was found in NPC cells, indicating that multiple cellular events were involved in parthenolide's anti-cancer activity. Previous studies demonstrated that COX-2 was a downstream signal in the NF-kB pathway $[31,49,50]$. Recently, it was revealed that NF- $\kappa B$ activation is involved in CD133-related COX-2 upregulation, suggesting that COX-2 performs important functions in tumorigenesis by means of the NF-kB-mediated pathway $[49,50]$. These findings, that parthenolide downregulated COX-2 by inhibiting the activity of the NF- $\kappa B$ signaling pathway, were supported in the present study (Fig. 12). Taken together, these data confirmed that parthenolide preferentially targets CSC-like SP cells and their self-renewal via molecular events such as the inhibition of NF- $\mathrm{KB}$ signaling activation and COX-2 expression.

In summary, the present study demonstrated that COX-2, as a potential biomarker for theranostics of NPC, plays a critical role in cancer stem-like SP cells of NPC. Moreover, parthenolide preferentially targeted the CSC-like SP cells and inhibited their cancer stemness properties, through downregulation of COX-2 and inhibition of the NF-kB-mediated pathway. Therefore, our study hinted that CSC-targeted chemotherapy through the NF- $\mathrm{B} / \mathrm{COX}-2$ pathways may be a novel strategy for the theranostics of NPC.

\section{Abbreviations}

5-FU: 5-fluorouracil; ABCG2: ATP-binding cassette sub-family G member 2; ANOVA: one-way analysis of variance; BCA: bicinchoninic acid; CFE: colony formation efficiency; COX-2: cyclooxygenase-2; CSC: cancer stem cell; DMSO: dimethyl sulfoxide; EDTA: ethylenediaminetetraacetic acid; FBS: fetal bovine serum; $\mathrm{IC}_{50}$ : concentration causing $50 \%$ inhibition; IкB $\alpha$ : inhibitor of kappa B alpha; IKK: ІкB kinase; MDR1: multidrug resistance protein 1 ; NC: negative control; NF-кB: nuclear factor-kappa B; NOD/SCID: nonobese diabetic/severe combined 
immunodeficient; NPC: nasopharyngeal carcinoma; NSP: non-side population; OD: optical density; p65: NF-кB p65; PDTC: pyrrolidine dithiocarbamate; PGE2: prostaglandin E2; p-ІкB $\alpha$ : phospho-I $\mathrm{B} \alpha$; p-IKK $\alpha / \beta$ : phospho-IKK $\alpha / \beta$; PN: parthenolide; p-p65: phospho-p65; PTGS2: prostaglandin-endoperoxide synthase 2 gene; qRT-PCR: quantitative real-time polymerase chain reaction; RT-PCR: reverse transcription polymerase chain reaction; $\mathrm{SD}$ : standard deviation; SDS-PAGE: sodium dodecyl sulfate-polyacrylamide gel electrophoresis; shRNA: short hairpin RNA; siRNA: small-interfering RNA; SP: side population; TNF- $\alpha$ : tumor necrosis factor- $\alpha$.

\section{Acknowledgements}

We thank Drs. Lei Guo and William Melchior for their critical reading of the manuscript. This work was supported by grants from the National Natural Science Foundation of China (NSFC Nos. 81172705, 81072334, 81472997), Key Program (No. 81130052) of NSFC, Early-stage Project of National Key Basic Research Program of China (No. 2014CB560710), the Key Project of Natural Science Foundation of Guangdong (No. S2011020002769), the Natural Science Foundation of Fujian Province of China (No. 2014J01372).

\section{Competing Interests}

The authors have declared that no competing interest exists.

\section{References}

1. Wei WI, Sham JS. Nasopharyngeal carcinoma. Lancet. 2005; 365: 2041-54. doi:10.1016/S0140-6736(05)66698-6.

2. Spano JP, Busson P, Atlan D, Bourhis J, Pignon JP, Esteban C, et al. Nasopharyngeal carcinomas: an update. Eur J Cancer. 2003; 39: 2121-35. doi:10.1016/S0959-8049(03)00367-8.

3. Bensouda Y, Kaikani W, Ahbeddou N, Rahhali R, Jabri M, Mrabti H, et al. Treatment for metastatic nasopharyngeal carcinoma. Eur Ann Otorhinolaryngol Head Neck Dis. 2011; 128: 79-85. doi:10.1016/j.anorl.2010.10.003.

4. Wilson BJ, Schatton T, Frank MH, Frank NY Colorectal Cancer Stem Cells: Biology and Therapeutic Implications. Curr Colorectal Cancer Rep. 2011; 7: 128-35. doi:10.1007/s11888-011-0093-2.

5. Tirino V, Desiderio V, Paino F, De Rosa A, Papaccio F, La Noce M, et al. Cancer stem cells in solid tumors: an overview and new approaches for their isolation and characterization. FASEB J. 2013; 27: 13-24. doi:Doi 10.1096/Fj.12-218222.

6. Kakarala M, Wicha MS. Cancer stem cells: implications for cancer treatment and prevention. Cancer J. 2007; 13: 271-5. doi:10.1097/PPO.0b013e318156da4e.

7. Reya T, Morrison SJ, Clarke MF, Weissman IL. Stem cells, cancer, and cancer stem cells. Nature. 2001; 414: 105-11. doi:10.1038/35102167.

8. Mannelli G, Gallo O. Cancer stem cells hypothesis and stem cells in head and neck cancers. Cancer Treat Rev. 2012; 38: 515-39. doi:DOI 10.1016/j.ctrv.2011.11.007.

9. Zhou S, Schuetz JD, Bunting KD, Colapietro AM, Sampath J, Morris JJ, et al. The $\mathrm{ABC}$ transporter Bcrp1/ABCG2 is expressed in a wide variety of stem cells and is a molecular determinant of the side-population phenotype. Nat Med. 2001; 7: 1028-34. doi:10.1038/nm0901-1028

10. Wang J, Guo LP, Chen LZ, Zeng YX, Lu SH. Identification of cancer stem cell-like side population cells in human nasopharyngeal carcinoma cell line. Cancer Res. 2007; 67: 3716-24. doi:10.1158/0008-5472.can-06-4343.

11. Wu C, Alman BA. Side population cells in human cancers. Cancer Lett. 2008; 268: 1-9. doi:10.1016/j.canlet.2008.03.048.

12. Ho MM, Ng AV, Lam S, Hung JY. Side population in human lung cancer cell lines and tumors is enriched with stem-like cancer cells. Cancer Res. 2007; 67: 4827-33. doi:10.1158/0008-5472.CAN-06-3557.

13. Knight DW. Feverfew: chemistry and biological activity. Nat Prod Rep. 1995; 12: 271-6. doi: 10.1039/NP9951200271.

14. Zhang S, Lin ZN, Yang CF, Shi X, Ong CN, Shen HM. Suppressed NF-kappaB and sustained JNK activation contribute to the sensitization effect of parthenolide to TNF-alpha-induced apoptosis in human cancer cells. Carcinogenesis. 2004; 25: 2191-9. doi:10.1093/carcin/bgh234.

15. Lesiak K, Koprowska K, Zalesna I, Nejc D, Duchler M, Czyz M. Parthenolide, a sesquiterpene lactone from the medical herb feverfew, shows anticancer activity against human melanoma cells in vitro. Melanoma Res. 2010; 20: 21-34. doi:10.1097/CMR.0b013e328333bbe4.

16. Zuch D, Giang AH, Shapovalov Y, Schwarz E, Rosier R, O'Keefe R, et al. Targeting radioresistant osteosarcoma cells with parthenolide. J Cell Biochem. 2012; 113: 1282-91. doi:10.1002/jcb.24002

17. Guzman ML, Rossi RM, Karnischky L, Li X, Peterson DR, Howard DS, et al. The sesquiterpene lactone parthenolide induces apoptosis of human acute myelogenous leukemia stem and progenitor cells. Blood. 2005; 105: 4163-9. doi:10.1182/blood-2004-10-4135.

18. Guzman ML, Rossi RM, Neelakantan $\mathrm{S}, \mathrm{Li}$ X Corbett CA, Hassane DC, et al. An orally bioavailable parthenolide analog selectively eradicates acute myelogenous leukemia stem and progenitor cells. Blood. 2007; 110: 4427-35. doi:10.1182/blood-2007-05-090621.

19. Birnie R, Bryce SD, Roome C, Dussupt V, Droop A, Lang SH, et al. Gene expression profiling of human prostate cancer stem cells reveals a pro-inflammatory phenotype and the importance of extracellular matrix interactions. Genome Biol. 2008; 9: R83. doi:10.1186/gb-2008-9-5-r83.

20. Ghantous A, Sinjab A, Herceg Z, Darwiche N. Parthenolide: from plant shoots to cancer roots. Drug Discov Today. 2013; 18: 894-905. doi:10.1016/j.drudis.2013.05.005.

21. Zhou J, Zhang H, Gu P, Bai J, Margolick JB, Zhang Y. NF-kappaB pathway inhibitors preferentially inhibit breast cancer stem-like cells. Breast Cancer Res Treat. 2008; 111: 419-27. doi:10.1007/s10549-007-9798-y.

22. Czyz M, Koprowska K, Sztiller-Sikorska M. Parthenolide reduces the frequency of ABCB5-positive cells and clonogenic capacity of melanoma cells from anchorage independent melanospheres. Cancer Biol Ther. 2013; 14: 135-45. doi:10.4161/cbt 22952

23. Curry EA 3rd, Murry DJ, Yoder C, Fife K, Armstrong V, Nakshatri H, et al. Phase I dose escalation trial of feverfew with standardized doses of parthenolide in patients with cancer. Invest New Drugs. 2004; 22: 299-305. doi:10.1023/B:DRUG.0000026256.38560 be.

24. Murphy JJ, Heptinstall S, Mitchell JR. Randomised double-blind placebo-controlled trial of feverfew in migraine prevention. Lancet. 1988; 2 : 189-92. doi:10.1016/S0140-6736(88)92289-1.

25. Ghosh S, Hayden MS. Celebrating 25 years of NF-kappaB research. Immunol Rev. 2012; 246: 5-13. doi:10.1111/j.1600-065X.2012.01111.x.

26. Karin M. Nuclear factor-kappaB in cancer development and progression. Nature. 2006; 441: 431-6 doi:10.1038/nature04870.

27. Sun W, Guo MM, Han P, Lin JZ, Liang FY, Tan GM, et al. Id-1 and the p65 subunit of NF-kappaB promote migration of nasopharyngeal carcinoma cells and are correlated with poor prognosis. Carcinogenesis. 2012; 33: 810-7. doi:10.1093/carcin/bgs027.

28. Guzman ML, Neering SJ, Upchurch D, Grimes B, Howard DS, Rizzieri DA, et al. Nuclear factor-kappaB is constitutively activated in primitive human acute myelogenous leukemia cells. Blood. 2001; 98: 2301-7. doi:10.1182/blood.V98.8.2301

29. Zhou J, Zhang Y. Cancer stem cells: Models, mechanisms and implications for improved treatment. Cell Cycle. 2008; 7: 1360-70 doi:10.4161/cc.7.10.5953.

30. Salati S, Risueno RM, Bhatia M. Targeting LSCs: powering an old tool. Blood. 2008; 111: 5423-4. doi:10.1182/blood-2008-03-144063.

31. Smith WL, DeWitt DL, Garavito RM. Cyclooxygenases: structural, cellular, and molecular biology. Annu Rev Biochem. 2000; 69: 145-82. doi:10.1146/annurev.biochem.69.1.145.

32. Williams CS, Mann M, DuBois RN. The role of cyclooxygenases in inflammation, cancer, and development. Oncogene. 1999; 18: 7908-16. doi:10.1038/sj.onc.1203286.

33. Greenhough A, Smartt HJ, Moore AE, Roberts HR, Williams AC, Paraskeva C, et al. The COX-2/PGE2 pathway: key roles in the hallmarks of cancer and adaptation to the tumour microenvironment. Carcinogenesis. 2009; 30: 377-86. doi:10.1093/carcin/bgp014.

34. Ma HI, Chiou SH, Hueng DY, Tai LK, Huang PI, Kao CL, et al. Celecoxib and radioresistant glioblastoma-derived CD133+ cells: improvement in radiotherapeutic effects. Laboratory investigation. J Neurosurg. 2011; 114: 651-62. doi:10.3171/2009.11.JNS091396.

35. Muraki $\mathrm{C}$, Ohga $\mathrm{N}$, Hida $\mathrm{Y}$, Nishihara $\mathrm{H}$, Kato $\mathrm{Y}$, Tsuchiya $\mathrm{K}$, et al. Cyclooxygenase-2 inhibition causes antiangiogenic effects on tumor endothelial and vascular progenitor cells. Int J Cancer. 2012; 130: 59-70. doi:Doi 10.1002/Ijc.25976.

36. Pang LY, Gatenby EL, Kamida A, Whitelaw BA, Hupp TR, Argyle DJ. Global gene expression analysis of canine osteosarcoma stem cells reveals a novel role for COX-2 in tumour initiation. PLoS One. 2014; 9: e83144. doi:10.1371/journal.pone.0083144.

37. Root DE, Hacohen N, Hahn WC, Lander ES, Sabatini DM. Genome-scale loss-of-function screening with a lentiviral RNAi library. Nat Methods. 2006; 3: 715-9. doi:10.1038/nmeth924.

38. Livak KJ, Schmittgen TD. Analysis of relative gene expression data using real-time quantitative PCR and the 2(-Delta Delta C(T)) method. Methods. 2001; 25: 402-8. doi:10.1006/meth.2001.1262.

39. Masferrer JL, Zweifel BS, Manning PT, Hauser SD, Leahy KM, Smith WG, et al. Selective inhibition of inducible cyclooxygenase 2 in vivo is 
antiinflammatory and nonulcerogenic. Proc Natl Acad Sci U S A. 1994; 91: 3228-32. doi:10.1073/pnas.91.8.3228.

40. Habeeb AG, Praveen Rao PN, Knaus EE. Design and synthesis of 4,5-diphenyl-4-isoxazolines: novel inhibitors of cyclooxygenase-2 with analgesic and antiinflammatory activity. J Med Chem. 2001; 44: 2921-7. doi: $10.1021 / j m 0101287$.

41. Zhang S, Won YK, Ong CN, Shen HM. Anti-cancer potential of sesquiterpene lactones: bioactivity and molecular mechanisms. Curr Med Chem Anticancer Agents. 2005; 5: 239-49. doi:10.2174/1568011053765976.

42. Abdullah LN, Chow EK. Mechanisms of chemoresistance in cancer stem cells. Clin Transl Med. 2013; 2: 3. doi:10.1186/2001-1326-2-3.

43. Ma S, Lee TK, Zheng BJ, Chan KW, Guan XY. CD133+ HCC cancer stem cells confer chemoresistance by preferential expression of the Akt/PKB survival pathway. Oncogene. 2008; 27: 1749-58. doi:10.1038/sj.onc.1210811.

44. Ferrandina G, Lauriola L, Distefano MG, Zannoni GF, Gessi M, Legge F, et al. Increased cyclooxygenase-2 expression is associated with chemotherapy resistance and poor survival in cervical cancer patients. J Clin Oncol. 2002; 20: 973-81. doi: 10.1200/JCO.20.4.973.

45. Østergaard, Ernst A, Labouriau R, Dagiliené E, Krarup HB, Christensen M, et al. Cyclooxygenase-2, multidrug resistance 1, and breast cancer resistance protein gene polymorphisms and inflammatory bowel disease in the Danish $\begin{array}{llll}\text { population. Scand J Gastroenterol. 2009; 44: 65-73. } & \end{array}$ doi:10.1080/00365520802400826.

46. Sorokin A. Cyclooxygenase-2: potential role in regulation of drug efflux and multidrug resistance phenotype. Curr Pharm Des. 2004; 10: 647-57. doi:10.2174/1381612043453117.

47. Kang JH, Song $\mathrm{KH}$, Jeong $\mathrm{KC}$, Kim S, Choi C, Lee $\mathrm{CH}$, et al. Involvement of Cox-2 in the metastatic potential of chemotherapy-resistant breast cancer cells. BMC Cancer. 2011; 11: 334. doi:10.1186/1471-2407-11-334.

48. Soares MP, Muniappan A, Kaczmarek E, Koziak K, Wrighton CJ, Steinhauslin $\mathrm{F}$, et al. Adenovirus-mediated expression of a dominant negative mutant of p65/RelA inhibits proinflammatory gene expression in endothelial cells without sensitizing to apoptosis. J Immunol. 1998; 161: 4572-82.

49. Annabi B, Laflamme C, Sina A, Lachambre MP, Beliveau R. A MT1-MMP/NF-kappaB signaling axis as a checkpoint controller of COX-2 expression in CD133+ U87 glioblastoma cells. J Neuroinflammation. 2009; 6: 8. doi:10.1186/1742-2094-6-8.

50. Murono $\mathrm{S}$, Inoue $\mathrm{H}$, Tanabe $\mathrm{T}$, Joab I, Yoshizaki $\mathrm{T}$, Furukawa $\mathrm{M}$, et al. Induction of cyclooxygenase-2 by Epstein-Barr virus latent membrane protein 1 is involved in vascular endothelial growth factor production in nasopharyngeal carcinoma cells. Proc Natl Acad Sci U S A. 2001; 98: 6905-10. doi:10.1073/pnas.121016998. 